\title{
Adaptive expression of uncoupling protein 1 in the carp liver and kidney in response to changes in ambient temperature.
}

\section{$\operatorname{AUTHOR}(S)$ :}

Murakami, Masaru; Ohi, Masahiro; Ishikawa, Shoko; Shirai, Mitsuyuki; Horiguchi, Hiroki; Nishino, Yoshii; Funaba, Masayuki

\section{CITATION:}

Murakami, Masaru ... [et al]. Adaptive expression of uncoupling protein 1 in the carp liver and kidney in response to changes in ambient temperature.. Comparative biochemistry and physiology. Part A, Molecular \& integrative physiology 2015, 185: 142-149

\section{ISSUE DATE:}

2015-04-10

\section{URL:}

http://hdl.handle.net/2433/198737

\section{RIGHT:}

(c) 2015 Elsevier Inc. Licensed under the Creative Commons Attribution-NonCommercial-NoDerivatives 4.0 International http://creativecommons.org/licenses/by-nc-nd/4.0/. NOTICE: this is the author's version of a work that was accepted for publication in [Comparative biochemistry and physiology. Part A, Molecular \& integrative physiology]. Changes resulting from the publishing process, such as peer review, editing, corrections, structural formatting, and other quality control mechanisms may not be reflected in this document Changes may have been made to this work since it was submitted for publication. A definitive version was subsequently published in [Comparative biochemistry and physiology. Part A, Molecular \& integrative physiology, Volume 185, Pages 142-149], doi:10.1016/j.cbpa.2015.04.003.: 許 諾条件により本文ファイルは2016-04-10に公開.;この論文は出版社版でありません。引用の際には出版社版をご確認 ご利用ください。; This is not the publi... 
Adaptive expression of uncoupling protein 1 in the carp liver and kidney in response to changes in ambient temperature

Masaru Murakami ${ }^{1 \star}$, Masahiro Ohi ${ }^{1}$, Shoko Ishikawa ${ }^{1}$, Mitsuyuki Shirai ${ }^{2}$, Hiroki Horiguchi $^{1}$, Yoshii Nishino ${ }^{3}$ and Masayuki Funaba ${ }^{4 \star}$

${ }^{1}$ Laboratory of Molecular Biology, Azabu University School of Veterinary Medicine, Sagamihara 252-5201, Japan

${ }^{2}$ Laboratory of Veterinary Pharmacology, Azabu University School of Veterinary Medicine, Sagamihara 252-5201, Japan

${ }^{3}$ Department of Animal Medical Sciences, Faculty of Life Sciences, Kyoto Sangyo University, Kyoto 603-8555, Japan

${ }^{4}$ Division of Applied Biosciences, Graduate School of Agriculture, Kyoto University, Kyoto 606-8502, Japan

Running title: Carp UCP1 Expression Related to Ambient Temperature Key words: UCP1, PPAR, PGC-1, RXR, ambient temperature, carps

*:correspondence

Masaru_Murakami (murakami@azabu-u.ac.jp) or Masayuki Funaba (mfunaba@kais.kyoto-u.ac.jp) 


\section{Abstract}

The expression of uncoupling protein (UCP1) is up-regulated in mammalian brown adipocytes during cold exposure. However, a previous study revealed that UCP1 was highly expressed in the liver of common carps, and that the hepatic expression of UCP1 was down-regulated during cold exposure. The present study examined the effects of temperature on the recovery of UCP1 expression levels and the expression of genes involved in UCP1 transcription in the livers and kidneys of common carps. The hepatic and renal expression of UCP1 was decreased by acclimation from $22^{\circ} \mathrm{C}$ to $8^{\circ} \mathrm{C}$, and a subsequent increase in the water temperature from $8^{\circ} \mathrm{C}$ to $28^{\circ} \mathrm{C}$ recovered the renal, but not hepatic expression of UCP1. Changes in the expression of peroxisome proliferator-activator receptor (PPAR) $\gamma$, retinoid X receptor (RXR) $\alpha$ and PPAR $\gamma$ co-activator (PGC)-1 $\alpha$, genes that are involved in the expression of UCP1 in mammals, with ambient temperature indicated that the expressions of PPAR $\gamma$ and RXR $\alpha$, but not expression of PGC-1 $\alpha$ was decreased in response to cold exposure; the hepatic and renal expressions of PPAR $\gamma$ and $\mathrm{RXR} \alpha$ recovered to basal levels with the cessation of cold exposure, although this was not complete for hepatic expression of PPAR $\gamma$. Cold exposure increased the expressions of PPAR $\beta / \delta$ and NRF1 both in the liver and kidney, as well as renal PGC-1 $\alpha$ expression, and subsequent increases in the water temperature from $8^{\circ} \mathrm{C}$ to $28^{\circ} \mathrm{C}$ decreased these expression levels. The results of the present study indicate that a unique regulatory mechanism is responsible for the hepatic and renal expression of carp UCP1 during cold exposure and subsequent reacclimation, and is distinct from that in murine brown adipocytes. 


\section{Introduction}

Uncoupling protein (UCP) 1 increases proton leakage from the mitochondrial inner membrane, resulting in a decreased proton motive force, which leads to increased oxygen consumption and heat generation without the concomitant generation of ATP. The restricted expression of UCP1 in mammalian brown adipocytes located in brown and white fat renders these cells responsible for non-shivering heat production (Cannon and Nedergaard, 2004).

The expression of UCP1 and its orthologs has been detected not only in placental mammals, but also in ectothermic vertebrates (Gesta et al., 2007). UCP1 was identified in the common carp (Cyprinus carpio), an ectothermic vertebrate, based on the conserved synteny within the mammalian lineage (Jastroch et al., 2005). It was found to be highly expressed in the liver and to a lesser extent in the kidney. The expression of UCP1 could not be detected in carp adipose tissues, which suggested that the role of UCP1 in energy expenditure in fish differed from that in placental mammals (Jastroch et al., 2005).

The expression of UCP1 in murine brown fat was previously shown to be up-regulated in response to cold exposure (Puigserver et al., 1998; Barbatelli et al., 2010), whereas hepatic UCP1 transcript levels were lower in the common carp acclimated at $8^{\circ} \mathrm{C}$ for 4 weeks than in those kept at $20^{\circ} \mathrm{C}$ (Jastroch et al., 2005). Similar responses were observed in gilthead sea bream (Sparus aurata); expression levels of hepatic UCP1 were lower in winter than in summer and fall (Bermejo-Nogales et al., 2010). The mechanism underlying the regulation of fish UCP1 expression currently remains unknown. In addition, changes in UCP1 expression upon recovery from cold exposure have not experimentally been examined. Furthermore, studies are needed to elucidate the relationship between the expression of UCP1 and non-shivering heat production in 
ectothermic vertebrates.

In murine brown fat, the transcription of UCP1 is regulated by several key molecules including the tissue-restricted transcription factors peroxisome proliferator-activator receptor (PPAR) $\alpha, \beta / \delta$ and $\gamma$, thyroid hormone receptor (TR) $\alpha$, and the transcriptional co-activator PPAR $\gamma$ co-activator (PGC)-1 $\alpha$ (Puigserver et al., 1998; Barbera et al., 2001; Cannon and Nedergaard, 2004; Cao et al., 2004; Komatsu et al., 2010; Seebacher and Glanville, 2010). In addition, PGC-1 $\beta$, a molecule structurally related to PGC-1 $\alpha$, is known to be highly expressed in murine brown fat (Lin et al., 2002; Seale et al., 2007). PPAR and TR heterodimerize with retinoid X receptor (RXR), and the formed complex regulates transcription of target genes including UCP1 and PGC-1 (Cannon and Nedergaard, 2004; Evans and Mangelsdorf, 2014). Furthermore, a transcription factor, cAMP responsive element binding protein (CREB) is phosphorylated and activated by protein kinase A, which leads to stimulation of UCP1 transcription (Cannon and Nedergaard, 2004). The expression levels of nuclear respiratory factor 1 (NRF1), which stimulates mitochondrial biogenesis by interacting with PGC-1 $\alpha$ (Scarpulla, 2008), have been closely related to those of UCP1, PPAR $\delta$ and PGC-1 $\alpha$ during cold exposure in murine brown fat (Seebacher and Glanville, 2010).

We hypothesized that regulation of carp UCP1 expression is similar to that established in murine UCP1 expression, although response to cold exposure is different between common carps and mice. As the first step to clarify regulation of fish UCP1 expression, we isolated not only 5' flanking region of carp UCP1 gene but also coding region of carp mRNA for several molecules involved in regulation of murine UCP1 expression partially, because the information has not yet been available yet. By use of the information, we examined the effects of ambient temperature on expression levels of 
UCP1 and the candidates to regulate UCP1 expression in common carps.

\section{Materials and methods}

\section{Animals}

A total of 30 common carps aged 7 months were used. These carps were fed commercial pellets ad libitum with a 12-h light/12-h dark cycle. They were kept in a temperature-controlled recirculating water system maintained at $22^{\circ} \mathrm{C}$ for at least 2 weeks (day 0). The water temperature was gradually lowered to $8^{\circ} \mathrm{C}$ over 3 days. After 14 days at $8^{\circ} \mathrm{C}$ (days 3-17), the water temperature was gradually returned to $28^{\circ} \mathrm{C}$ over 3-5 days and kept at $28^{\circ} \mathrm{C}$ for 14 days (days 21-35). Carps were sacrificed on days 0,17 , and 35, and the livers and kidneys were removed.

\section{RNA isolation and RT-quantitative real-time PCR}

RNA isolation and reverse transcription (RT)-quantitative real-time PCR (qPCR) analyses were performed as described previously (Murakami et al., 2008; Asai et al., 2014). Total RNA was isolated from the livers and kidneys of carps using QuickGene RNA tissue kit S (Wako, Osaka, Japan) in QuickGene-810 (Wako, Osaka, Japan), an automatic nucleic acid extraction system, according to the manufacturer' s protocol. The concentration of RNA was determined from absorbance at $260 \mathrm{~nm}$. In RT-qPCR analyses, cDNA was synthesized using the high capacity cDNA reverse transcription kit with an RNase inhibitor (Life Technologies, Carlsbad, CA, USA), according to the manufacturer's protocol. The cDNA corresponding to $5 \mathrm{ng}$ of total RNA was used as a template of qPCR; the qPCR was performed using KAPA SYBR FAST Universal qPCR Master Mix (Kapa Biosystems, Boston, MA, USA) in Thermal Cycler Dice Real Time System TP800 (Takara, Otsu, Japan), according to the manufacturer's protocol. The qPCR profile was as follows: after denaturing for $30 \mathrm{~s}$ at $95{ }^{\circ} \mathrm{C}, 40$ cycles consisted of 5 
$\mathrm{s}$ at $95{ }^{\circ} \mathrm{C}$ and $30 \mathrm{~s}$ at $60^{\circ} \mathrm{C}$. The oligonucleotide primers for qPCR are shown in Table 1. After 40 cycles of RT-qPCR, the dissociation (melting) curve of the products was examined by changes in the ramp temperature from $60^{\circ} \mathrm{C}$ to $95^{\circ} \mathrm{C}$. Each sample showed a single peak, suggesting the expected PCR products. The mRNA levels were expressed relative to EF1 $\alpha$ mRNA levels, and the expression level in the liver of control carps was set at 100 .

Isolation of 5' flanking region of UCP1 gene from carps

The 5' flanking region of carp UCP1 gene was isolated by two rounds of PCR; we designed 4 PCR primers. Because of lack of information on 5' flanking region of carp UCP1 gene, forward primers were designed on the basis of information of zebrafish UCP1 gene; 5' -gttgtagttttggtttattacacaagg-3' named as primer A that corresponds to nt -4500 to nt -4474 of zebrafish UCP1 gene (GenBank accession number NC_007112) and 5'-taaagtcctgctgcagtggaaacag-3' as primer B that is nt -3000 to nt -2976 of zebrafish UCP1 gene. The reverse primers were designed based on the carp UCP1 gene (AY461434), i.e., 5'-gatggagtgacaggatgatgcctcgtg-3' (nt +45 to $\mathrm{nt}+19$ ) and 5'-ctgacagctgtgattgagttcctctg-3' (nt +74 to $n t+49$ ) as primer C and primer D, respectively. The first round PCR was performed using genomic DNA, which was isolated from carp muscle cells, as a template DNA as well as primers A and D; PCR was conducted in a total volume of $50 \mu \mathrm{L}$ by use of PrimeSTAR GXL DNA Polymerase that is a high fidelity polymerase (TaKaRa). The PCR profile consisted of 35 cycles of denature for $10 \mathrm{sec}$ at $98^{\circ} \mathrm{C}$, annealing for $15 \mathrm{sec}$ at $55^{\circ} \mathrm{C}$ and extension for $4 \mathrm{~min}$ at $68^{\circ} \mathrm{C}$. The second round of PCR re-amplified using one-fiftieth of the PCR products as the template, and primers $\mathrm{B}$ and $\mathrm{C}$ with the same PCR profile. The products of the nested-PCR were electrophoresed in agarose gels, followed by ethidium bromide staining and visualization under ultraviolet light. A significant band was detected at 2800 bp, which was within the range of expected size. The band was excised from the 
gels, and the nucleotide sequence was determined by direct sequencing and deposited in GenBank (LC003596). To examine the validity of sequence, PCR was performed by use of genomic DNA as a template DNA and PCR primers spanning nt -434 to nt -412 (5'-tttctgagctcctttaatgcatc-3') and nt +930 to nt +908 (5'-gcggtgtccagagggaaggtgac-3'), and the nucleotide sequence of PCR product was confirmed by direct sequencing. The 5' flanking region of carp, human, mouse, rat and zebrafish UCP gene was compared by use of Pairwaise Sequence Alignment of EMBOSS (http://emboss.open-bio.org/).

Isolation of PGC-1 $\alpha$, PGC-1 $\beta, \mathrm{PPAR} \beta / \delta, \mathrm{TR} \alpha, \mathrm{RXR} \alpha, \mathrm{CREB}$ and NRF1 mRNA from carp livers

To isolate PGC- $1 \alpha$, PGC- $1 \beta$, PPAR $\beta / \delta$, TR $\alpha$, RXR $\alpha$, CREB and NRF1 cDNA from carp livers, $1 \mu \mathrm{g}$ of the recovered RNA was treated with RNase-free DNase I (Invitrogen) to remove residual DNA. RNA was subsequently reverse-transcribed in a $21 \mu \mathrm{l}$ volume reaction using the oligo(dT) primer and SuperscriptIII First-Strand Synthesis System for RT-PCR (Invitrogen) to generate first-strand cDNA (Murakami et al., 2008).

Based on the nucleotide sequence of the PGC- $1 \alpha$ mRNAs of goldfish (Carassius auratus, FJ710611 and EU426842), zebrafish (Danio rerio, FJ710604), grass carp (Ctenopharyngodon idella, JN195739), and golden shiner (Notemigonus crysoleucas, FJ710606), the following PCR primers were designed to isolate PGC-1 $\alpha$ cDNA: 5'-atggcgtgggacaggtgtaatc-3' and 5'-tcaaaggaagtggcaagatggt-3'. To isolate PGC-1ß mRNA, the following PCR primers were designed based on the nucleotide sequence of zebrafish PGC-1 $\beta$ (XM_003199895): 5'-atggcggactgcgcttcactgttagatg-3' and 5'-agacccccgactccgtcctcaacaat-3'. To isolate PPAR $\beta / \delta$ mRNA, the PCR primers, 5'-cagtgcaccacagtggaaactg-3' and 5'-gaatgccatcctgaatctgctc-3', were designed based on the nucleotide sequence of zebrafish PPARSb (NM_131468 and XM_683192). The 
mRNA of TR $\alpha$ was isolated on the bases of nucleotide sequences of goldfish TR $\alpha 1$

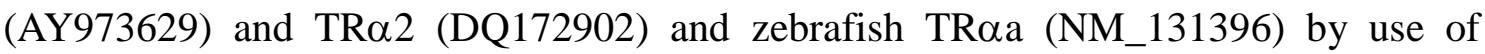
5'-gcatcacatgtgagggctgcaa-3' and 5'-tctccatacagcagcctttcag-3' as PCR primers. The mRNA of RXR $\alpha$ was isolated on the bases of nucleotide sequences of goldfish RXR $\alpha$ (AY197562) and zebrafish RXR $\alpha$ a (NM_001161551 and XM_001923838) by use of 5'-cagaagtgtttggccatgggc-3' and 5'-gcaaaccttccaggttgttcag-3' as PCR primers. The mRNA of CREB was isolated on the bases of nucleotide sequences of goldfish CREB1 (AM886438) and zebrafish CREB1 (NM_001161551 and XM_001923838) by use of 5'-caggagcagatgtccagcagg-3' and 5'-gcatactgcaggatggtggtg-3' as PCR primers. As for NRF1 mRNA, the following PCR primers were designed based on the nucleotide sequence of zebrafish NRF1 (XM_005164709) and Japanese pufferfish (Takifugu rubripes) NRF1-like isoform 1 (XM_003972802): 5'-caggcccagctccgagcgttcat-3' and 5'-ggccacagcctgcgtggcctct-3'. Using these primers, cDNA was isolated from common carp livers, and agarose gel electrophoresis of the PCR products indicated bands with an expected size of $\sim 920$ bp for PGC-1 $\alpha, \sim 350$ bp for PGC-1 $\beta, \sim 270$ bp for PPAR $\beta / \delta$, $\sim 440$ bp for TR $\alpha, \sim 450$ bp for RXR $\alpha, \sim 440$ bp for CREB and 560 bp for NRF1. The nucleotide sequence of the PCR product was determined by direct sequencing.

\section{Statistical analyses}

Data are expressed as the mean \pm SE. Data were log-transformed to provide an approximation of a normal distribution before analysis. Differences between groups in each tissue were analyzed by Tukey's multiple comparison test. $P<0.05$ was considered significant.

\section{Results}

The expression of UCP1 was evaluated in the livers and kidneys of common carps 
acclimatized at various temperatures (Fig. 1). A decrease in the water temperature from $22^{\circ} \mathrm{C}$ to $8^{\circ} \mathrm{C}$ significantly reduced the expression of UCP1 in the liver and kidney within 14 days. Although increasing the water temperature from $8^{\circ} \mathrm{C}$ to $28^{\circ} \mathrm{C}$ did not change the hepatic expression of UCP1, the renal expression of UCP1 returned to basal levels. Consistent with previous findings (Jastroch et al., 2005), the expression level of UCP1 was higher in the liver than in the kidney.

Expression of mammalian UCP1 gene is transcriptionally regulated (Cannon and Nedergaard, 2004). We determined nucleotide sequence of 5' flanking region of carp UCP1 gene, because it has not yet been available. Whole genome sequence of common carps is not known, and, therefore, we isolated 2634 bases upstream sequence of the putative transcriptional initiation site of carp UCP1 through the nested-PCR strategy in reference to the nucleotide sequence of 5' flanking region of zebrafish UCP1 gene (Fig. 2A). When genomic DNA from three carps was individually used as the template DNA, comparable results were obtained (data not shown). The validity of the isolated nucleotide sequence was also determined by the expected amplification of genomic DNA using PCR primers designed within the region of determined nucleotide (data not shown).

The nucleotide sequence indicated the lack of the first 18 bases (5'-tggatccaaagaattcgg-3') within 5' untranslated region of carp UCP1 mRNA in GenBank accession number AY461434, and three nucleotide substitutions, T, C and T instead of A, G and G of the 20th, 22nd and 25th nucleotide, respectively. We performed RT-PCR using liver cDNA as the template DNA and the first 22 bases of AY461434 (primer E: 5'-tggatccaaagaattcggcacg-3') as the forward primer and primer for the RT-qPCR as the reverse primer, and found no band (Fig. 2B, lanes 1-3). In contrast, when the first 22 bases overlapping to AY461434 determined in this study (primer F: 
5'-ctccagtcatcatcctgtcact-3'), i.e., corresponding region spanning the 19th nucleotide to the 40th nucleotide of AY461434, were used as the forward primer, we detected the PCR product with the expected size (Fig. 2B, lanes 5-7). Therefore, we conclude that the 19th nucleotide of AY461434 is the putative transcriptional initiation site in common carps used in this study, and designated as nt +1 ; the difference of strain may be related to the difference of nucleotide sequence near 5' untranslated region of carp UCP mRNA. The nucleotide sequence has limited homology with that of 5' flanking region of human, mouse and rat UCP1 gene (Fig. 2C). The less homology of the nucleotide sequence was also detected between carps and zebrafish.

Previous studies identified and characterized the brown adipose tissue (BAT)-specific enhancer region ( 220 bp) around nt -2500 upstream of murine UCP1 transcriptional initiation site (Kozak et al., 1994; Sim and Kozak, 2002). The region plays a critical role in the regulation of UCP1 that includes responsive element to PPAR, TR and CREB (Cannon and Nedergaard, 2004). Homology search indicated no similarity between the murine BAT-specific enhancer and the carp UCP1 promoter (data not shown). In addition, there was no consensus responsive element to PPAR, TR and CREB within the carp UCP1 promoter, i.e., direct repeats (DR) 1 and 2 (core sequence 5'-agg(a/t)ca-3' separated by one and two base-pairs, respectively) for PPAR (Evans and Mangelsdolf, 2014), DR-4 for TR (Evans and Mangelsdolf, 2014) and cAMP response element (5'-tgacgtca-3') for CREB (Montminy, 1997). We also searched specific sequence motifs present in the murine BAT-specific enhancer region, and found two half-site consensus sequence of CRE (5'-cgtca-3' and its complementary sequence 5'-tgacg-3', Fig. 2A, underline), two contiguous TTCC motifs within brown adipocyte-regulatory element 1 (BRE-1, Fig. 2A, box), and two possible NF-E2 sites (Fig. 2A, double underline). 
The expression of genes involved in the expression of UCP1 in mammals (Puigserver et al., 1998; Barbera et al., 2001; Cannon and Nedergaard, 2004; Cao et al., 2004; Komatsu et al., 2010; Seebacher and Glanville, 2010) was examined next. Sequence information for common carp PGC- $1 \alpha$, PGC-1 $\beta$, PPAR $\beta / \delta$, TR $\alpha, \mathrm{RXR} \alpha, \mathrm{CREB}$ and NRF1 cDNAs was unavailable; thus, we isolated gene transcripts from the liver of the common carp. The partial amino acid sequences deduced from the nucleotide sequences exhibited sequence similarity to fish PGC- $1 \alpha$, PGC- $1 \beta, \operatorname{PPAR} \beta / \delta, \mathrm{TR} \alpha, \mathrm{RXR} \alpha, \mathrm{CREB}$ and NRF1, respectively (Fig. 3), which suggested that these are orthologs of respective genes in common carps. Since fish PGC- $1 \alpha$, PGC- $1 \beta, \operatorname{PPAR} \beta / \delta$, TR $\alpha, \mathrm{RXR} \alpha, \mathrm{CREB}$ and NRF1 consist of $\sim 878, \sim 495, \sim 517, \sim 421, \sim 343, \sim 318$ and $\sim 514$ amino acids, respectively, the gene transcripts clarified in the present study are expected to correspond to approximately one-fifth of PGC-1 $\beta$ and PPAR $\beta / \delta$, one-third of PGC- $1 \alpha$, TR $\alpha$ and NRF1, and half of RXR $\alpha$ and CREB of the coding regions.

Unlike the hepatic and renal expression of UCP1, the expression level of PGC-1 $\alpha$ did not decrease with a reduction in the water temperature from $22^{\circ} \mathrm{C}$ to $8^{\circ} \mathrm{C}$; the renal expression of PGC-1 $\alpha$ was increased by cold exposure (Fig. 4A). The hepatic expression of PGC-1 $\alpha$ remained unchanged by increases in the water temperature from $8^{\circ} \mathrm{C}$ to $28^{\circ} \mathrm{C}$, whereas the cold-induced expression of renal PGC- $1 \alpha$ returned to basal levels with increases in the water temperature from $8^{\circ} \mathrm{C}$ to $28^{\circ} \mathrm{C}$. Decreasing the water temperature from $22^{\circ} \mathrm{C}$ to $8^{\circ} \mathrm{C}$ decreased the expression of PGC- $1 \beta$ in the kidney, but not significantly in the liver (Fig. 4B). The renal expression of PGC-1 $\beta$ tended to return to basal levels with increases in the water temperature from $8^{\circ} \mathrm{C}$ to $28^{\circ} \mathrm{C}$.

The hepatic expression of PPAR $\alpha$ was unaffected by cold exposure, but decreased with increases in the water temperature from $8^{\circ} \mathrm{C}$ to $28^{\circ} \mathrm{C}$ (Fig. 5A). In contrast, changes in the water temperature did not affect the renal expression of PPAR $\alpha$. Expression of 
hepatic and renal PPAR $\beta / \delta$ was increased by cold exposure, and the increase in water temperature from $8^{\circ} \mathrm{C}$ to $28^{\circ} \mathrm{C}$ decreased the expressions; hepatic expression levels at $28^{\circ} \mathrm{C}$ were lower than those at $22^{\circ} \mathrm{C}$ (Fig. 5B). Both the hepatic and renal expression of PPAR $\gamma$ was markedly reduced with decreasing water temperature from $22^{\circ} \mathrm{C}$ to $8^{\circ} \mathrm{C}$, and the cessation of cold exposure returned to these expression levels back to basal levels; however, hepatic expression was not completely recovered (Fig. 5C). Expression of renal TR $\alpha$ was decreased during the cold exposure, and the cessation of cold exposure further decreased the expression; hepatic expression of TR $\alpha$ was also decreased by the increase in water temperature from $8^{\circ} \mathrm{C}$ to $28^{\circ} \mathrm{C}$ (Fig. 5D). Similar to the regulatory expression of PPAR $\gamma, \mathrm{RXR} \alpha$ expressions in the liver and kidney were significantly decreased during cold exposure, and the re-warming resulted in return to the basal expression levels (Fig. 5E).

Cold exposure did not affect expression levels of hepatic and renal expression of CREB, but the increase in water temperature from $8^{\circ} \mathrm{C}$ to $28^{\circ} \mathrm{C}$ significantly decreased renal CREB expression (Fig. 6A). The cold exposure increased the hepatic and renal expression levels of NRF1, and an increase in the water temperature from $8^{\circ} \mathrm{C}$ to $28^{\circ} \mathrm{C}$ decreased expression levels; expression levels at $28^{\circ} \mathrm{C}$ were lower than those at $22^{\circ} \mathrm{C}$ (Fig. 6B).

\section{Discussion}

This study revealed six aspects of the regulation of the hepatic and renal expression of UCP1 in carps in response to changes in ambient temperature 1) both the hepatic and renal expression of UCP1 was down-regulated by cold exposure, 2) expression levels in the kidney, but not in the liver recovered with the cessation of cold exposure, 3) water temperature-related changes in the renal expression of UCP1 paralleled those in the 
renal expression of PPAR $\gamma$ and $\mathrm{RXR} \alpha$, 4) the cold-induced down-regulation of hepatic PPAR $\gamma$ partially recovered with the cessation of cold exposure, 5) contrary to hepatic PPAR $\gamma$ and RXR $\alpha$ expressions, expressions of hepatic and renal PPAR $\beta / \delta$ and NRF1 were up-regulated during cold exposure, and the cessation of cold exposure returned the expression, and 6) the expression of hepatic and renal PGC-1 $\alpha$ was not decreased by cold exposure. Of these, the down-regulation observed in the hepatic expression of UCP1 during cold exposure was consistent with previous findings (Jastroch et al., 2005); considering that the common carp is an ectothermic animal, down-regulation of UCP1, a drive engine of non-shivering thermogenesis, during cold exposure is reasonable. The other 5 points were not evaluated in the study by Jastroch et al. (2005). Our results confirm that regulatory expression of carp UCP1 during cold exposure and subsequent recovery from cold exposure is distinct from that of mammalian UCP1 expression, but suggest that expression level of carp UCP1 is partly but not completely related to that of molecules involved in regulation of mammalian UCP1 expression. The present study has provided a novel insight into the regulatory expression of carp UCP1.

Although expression levels of UCP1 were closely related to those of molecules regulating UCP1 expression in murine brown adipocytes during the changes in ambient temperature in common carps, the detailed regulation was distinct between murine brown adipocytes and carp tissues such as liver and kidney. In murine brown adipocytes, the cold-induced stimulation of the sympathetic nervous system and accompanying $\beta 3$ adrenergic receptor activation induce the transcription of PGC-1 $\alpha$, which in turn stimulates UCP1 transcription through complex formation with PPAR $\gamma$ (Oberkofler et al., 2002; Cao et al., 2004). The expression level of PGC-1 $\alpha$, but not PPAR $\gamma$ was shown to increase during cold exposure in murine brown fat (Seale et al., 2007; Karamitri et al., 2009; Komatsu et al., 2010). The present study indicates that renal expression of UCP1 is closely related to that of PPAR $\gamma$ rather than PGC-1 $\alpha$; water temperature-related 
changes in the renal expression of UCP1 paralleled those in the expression of PPAR $\gamma$, but not PGC-1 $\alpha$. Cold exposure also decreased hepatic expressions of UCP1 and PPAR $\gamma$, but the expression level of hepatic PGC-1 $\alpha$ was unaffected.

Consistent with previous findings on the effects of cold on the expression of PPAR $\alpha$ in murine brown fat (Komatsu et al., 2010), the hepatic and renal expression levels of PPAR $\alpha$ in common carps were unaffected by cold exposure. In addition, hepatic and renal expressions of PPAR $\beta / \delta$ were rather increased during cold exposure. Taking the expression level of PPARs and PGC-1 $\alpha$ together, the down-regulation of PPAR $\gamma$ expression during cold exposure may be responsible for the down-regulation of UCP1 expression in common carps. Changes in expression levels of $\mathrm{RXR} \alpha$, a PPAR $\gamma$ partner (Evans and Mangelsdolf, 2014), basically paralleled to those of PPAR $\gamma$. Therefore, expression levels of RXR $\alpha$ may be also involved in regulation of UCP1 expression by PPAR $\gamma$ during cold exposure.

However, the regulatory expressions of PPAR $\gamma / \mathrm{RXR} \alpha$ do not explain UCP1 expression in liver of common carps during the water temperature from $8^{\circ} \mathrm{C}$ to $28^{\circ} \mathrm{C}$; the cessation of cold exposure increased hepatic expressions of PPAR $\gamma$ and RXR $\alpha$ but not UCP1. It is possible that inhibitory factor(s) on UCP1 expression is induced in carp livers during the recovery period from cold exposure.

We isolated 2634 bases upstream to putative transcription initiation site of UCP1 gene. The nucleotide sequence has low homology to corresponding region of humans, mice, rats and even zebrafish, although some sequence motifs in the murine BAT-specific enhancer are present scattered widely. The enhancer region of human UCP1 gene, which includes responsive elements to PPAR, TR and CREB, is located around nt -3800 (Rim and Kozak, 2002; Shore et al., 2013). It is possible that the transcriptional 
enhancer is located more distal region of UCP1 promoter. In addition, the sequence motifs in fish may not match to those suggested in mammals. These should be evaluated in future studies.

We also evaluated the expression of NRF1, because NRF1 has been shown to regulate energy metabolism in concert with PGC-1 $\alpha$ in mammals (Scarpulla, 2008). A previous study revealed that changes in NRF1 expression paralleled those in UCP1, PGC-1 $\alpha$ and PPAR $\delta$ expression during cold exposure and physical activity in murine brown fat (Seebacher and Glanville, 2010). Cold exposure increased the renal expression of PGC- $1 \alpha, \operatorname{PPAR} \beta / \delta$ and NRF1, and the cessation of cold exposure decreased the expression of these genes; similar changes were also detected in hepatic expressions of PPAR $\beta / \delta$ and NRF1. However, water temperature-related changes in the expression pattern of PGC- $1 \alpha$, PPAR $\beta / \delta$ and NRF1 differed from those in UCP1 expression. PGC-1 $\alpha, \operatorname{PPAR} \beta / \delta$ and NRF1 may cooperatively function through their up-regulation during cold exposure, and this is distinct from the regulation of energy metabolism through the modulation of UCP1 expression.

A previous study showed that the hepatic expressions of PGC- $1 \alpha$, PGC- $1 \beta$, and PPAR $\beta$ and NRF1 were higher in goldfish acclimated at $4^{\circ} \mathrm{C}$ for 3 weeks than in those acclimated at $20^{\circ} \mathrm{C}$, and PPAR $\alpha$ expression was lower during cold exposure (LeMoine et al., 2008). Bremer et al. (2012) observed that cold exposure significantly increased expression of PGC-1 $\beta$ and NRF1, decreased expression of PGC-1 $\alpha$, PPAR $\alpha$ and TR $\alpha$, and did not affect expression of PPAR $\beta / \delta$ and RXR $\alpha$ in white muscle of goldfish. The temperature-related changes in gene expression were partly but not completely consistent with the previous results. At present, it is difficult to understand relationships among expression levels of these genes comprehensively; effects of cold exposure are also different among tissues in gold fish (LeMoine et al., 2008), and there may be 
species differences on cold-related changes in gene expression.

Although carp UCP1 may be a functional uncoupling protein, similar to its mammalian counterpart (Jastroch et al., 2007), a correlation between the expression of UCP1 and non-shivering heat production has yet to be established in fish. Future studies are needed to determine the role of UCP1 expression, the physiological significance of regulatory changes in the hepatic and renal expression of UCP1, and the molecular mechanisms underlying altered expression levels of genes during cold exposure and subsequent recovery from cold exposure in common carps. Also, aging, diet, feed restriction and hypoxia are known to affect expression levels of UCP2 and UCP3, structurally related molecules to UCP1, in gilthead sea bream (Bermejo-Nogales et al., 2010, 2014). To understand uncoupling-related regulation of energy metabolism in ectothermic animals fully, it is needed to explore regulatory expressions of UCP2 and UCP3 in addition to UCP1.

\section{Acknowledgements}

We thank Dr. Masaaki Hasegawa for providing the common carps. Also, we are grateful to anonymous reviewer's constructive comments. This work was supported by a research project grant awarded by the Azabu University (2013K08).

\section{References}

Asai K, Funaba M, Murakami M. Enhancement of RANKL-induced MITF-E expression and osteoclastogenesis by TGF- $\beta$. Cell Biochem Funct. 2014 $32: 401-9$.

Barbatelli G, Murano I, Madsen L, Hao Q, Jimenez M, Kristiansen K, Giacobino JP, De 
Matteis R, Cinti S. The emergence of cold-induced brown adipocytes in mouse white fat depots is determined predominantly by white to brown adipocyte transdifferentiation. Am J Physiol Endocrinol Metab. 2010 298:E1244-53.

Barbera MJ, Schluter A, Pedraza N, Iglesias R, Villarroya F, Giralt M. Peroxisome proliferator-activated receptor $\alpha$ activates transcription of the brown fat uncoupling protein-1 gene. A link between regulation of the thermogenic and lipid oxidation pathways in the brown fat cell. J Biol Chem. 2001 276:1486-93.

Bermejo-Nogales A, Calduch-Giner JA, Pérez-Sánchez J. Gene expression survey of mitochondrial uncoupling proteins (UCP1/UCP3) in gilthead sea bream(Sparus aurata L.). J Comp Physiol B. 2010 180:685-94.

Bermejo-Nogales A, Calduch-Giner JA, Pérez-Sánchez J. Tissue-specific gene expression and functional regulation of uncoupling protein 2 (UCP2) by hypoxia and nutrient availability in gilthead sea bream (Sparus aurata): implications on the physiological significance of UCP1-3 variants. Fish Physiol Biochem. 2014 40:751-62.

Bremer K, Monk CT, Gurd BJ, Moyes CD. Transcriptional regulation of temperature-induced remodeling of muscle bioenergetics in goldfish. Am J Physiol Regul Integr Comp Physiol. 2012 303:R150-8.

Cannon B, Nedergaard J. Brown adipose tissue: function and physiological significance. Physiol Rev. 2004 84:277-359.

Cao W, Daniel KW, Robidoux J, Puigserver P, Medvedev AV, Bai X, Floering LM, Spiegelman BM, Collins S. p38 mitogen-activated protein kinase is the central regulator of cyclic AMP-dependent transcription of the brown fat uncoupling protein 1 gene. Mol Cell Biol. 2004 24:3057-67.

Evans RM, Mangelsdorf DJ. Nuclear receptors, RXR, and the big bang. Cell. 2014 157:255-66. 
Gesta S, Tseng YH, Kahn CR. Developmental origin of fat: tracking obesity to its source. Cell. 2007 131:242-56.

Jastroch M, Buckingham JA, Helwig M, Klingenspor M, Brand MD. Functional characterisation of UCP1 in the common carp: uncoupling activity in liver mitochondria and cold-induced expression in the brain. J Comp Physiol B. 2007 177:743-52

Jastroch M, Wuertz S, Kloas W, Klingenspor M. Uncoupling protein 1 in fish uncovers an ancient evolutionary history of mammalian nonshivering thermogenesis. Physiol Genomics. 2005 22:150-6.

Karamitri A, Shore AM, Docherty K, Speakman JR, Lomax MA. Combinatorial transcription factor regulation of the cyclic AMP-response element on the Pgc-1 $\alpha$ promoter in white 3T3-L1 and brown HIB-1B preadipocytes. J Biol Chem. 2009 284:20738-52.

Komatsu M, Tong Y, Li Y, Nakajima T, Li G, Hu R, Sugiyama E, Kamijo Y, Tanaka N, Hara A, Aoyama T. Multiple roles of PPAR $\alpha$ in brown adipose tissue under constitutive and cold conditions. Genes Cells. 2010 15:91-100.

Kozak UC, Kopecky J, Teisinger J, Enerbäck S, Boyer B, Kozak LP. An upstream enhancer regulating brown-fat-specific expression of the mitochondrial uncoupling protein gene. Mol Cell Biol. 1994 14:59-67.

LeMoine CM, Genge CE, Moyes CD. Role of the PGC-1 family in the metabolic adaptation of goldfish to diet and temperature. J Exp Biol. 2008 211:1448-55.

Lin J, Puigserver P, Donovan J, Tarr P, Spiegelman BM. Peroxisome proliferator-activated receptor gamma coactivator $1 \beta$ (PGC-1 $\beta$ ), a novel PGC-1-related transcription coactivator associated with host cell factor. J Biol Chem. 2002 277:1645-8.

Montminy M. Transcriptional regulation by cyclic AMP. Annu Rev Biochem. 1997 66:807-22. 
Murakami M, Kondo S, Funaba M. Expression and function of alternative splice variants of the mouse TGF- $\beta$ type I receptor. Cell Biol Int. 2008 32:848-54.

Oberkofler H, Esterbauer H, Linnemayr V, Strosberg AD, Krempler F, Patsch W. Peroxisome proliferator-activated receptor (PPAR) $\gamma$ coactivator-1 recruitment regulates PPAR subtype specificity. J Biol Chem. 2002 277:16750-7.

Puigserver P, Wu Z, Park CW, Graves R, Wright M, Spiegelman BM. A cold-inducible coactivator of nuclear receptors linked to adaptive thermogenesis. Cell. 1998 92:829-39.

Rim JS, Kozak LP. Regulatory motifs for CREB-binding protein and Nfe2l2 transcription factors in the upstream enhancer of the mitochondrial uncoupling protein 1 gene. J Biol Chem. 2002 277:34589-600.

Scarpulla RC. Transcriptional paradigms in mammalian mitochondrial biogenesis and function. Physiol Rev. 2008 88:611-38.

Seale P, Kajimura S, Yang W, Chin S, Rohas LM, Uldry M, Tavernier G, Langin D, Spiegelman BM. Transcriptional control of brown fat determination by PRDM16. Cell Metab. 2007 6:38-54.

Seebacher F, Glanville EJ. Low levels of physical activity increase metabolic responsiveness to cold in a rat (Rattus fuscipes). PLoS One. 2010 5:e13022.

Shore A, Emes RD, Wessely F, Kemp P, Cillo C, D'Armiento M, Hoggard N, Lomax MA. A comparative approach to understanding tissue-specific expression of uncoupling protein 1 expression in adipose tissue. Front Genet. 2013 3:304.

Tseng YH, Kokkotou E, Schulz TJ, Huang TL, Winnay JN, Taniguchi CM, Tran TT, Suzuki R, Espinoza DO, Yamamoto Y, Ahrens MJ, Dudley AT, Norris AW, Kulkarni RN, Kahn CR. New role of bone morphogenetic protein 7 in brown adipogenesis and energy expenditure. Nature. 2008 454:1000-4.

Xue B, Coulter A, Rim JS, Koza RA, Kozak LP. Transcriptional synergy and the regulation of Ucp1 during brown adipocyte induction in white fat depots. Mol 
Cell Biol. 2005 25:8311-22.

\section{Figure legends}

Fig. 1. UCP1 expression in the livers and kidneys of common carps acclimated to various temperatures

Common carps acclimated at $22^{\circ} \mathrm{C}$ were subjected to cold exposure for 14 days at $8^{\circ} \mathrm{C}$. They were then acclimated at $28^{\circ} \mathrm{C}$ for 14 days. The gene transcript levels of UCP1 were determined by RT-qPCR and are expressed relative to the expression of EF1 $\alpha$, with the hepatic level determined on day 0 (control) set to 100. Data shown are the mean \pm SE $(n=10)$. A, B and a, b: $P<0.05$.

Fig. 2. Nucleotide sequence of the 5' flanking region of the carp UCP1 gene (A) Nucleotide sequence of the 5' flanking region of the carp UCP1 gene. The nt +1 is defined as putative transcriptional-initiation site. Possible CRE, BRE-1 and NF-E2 recognition sequences are shown with underline, box and double underline, respectively. (B) RT-PCR analyses were performed using cDNA prepared from kidney (K: lanes 1 and 5) and liver (L: lanes 2, 3, 6 and 7) as the template. The cDNA was prepared by Superscript III First-Strand Synthesis System (S) to isolate full-length of carp UCP1 mRNA (lanes 1, 2, 5 and 6) or by high capacity cDNA reverse transcription kit (H: lanes 3 and 7). Lanes 1-3 and 5-7 indicate PCR products using primer E and the reverse primer for RT-qPCR, and primer F and the reverse primer for RT-qPCR, respectively. Lanes 4 and 8: negative control and 100-bp DNA ladder, respectively. (C) Homology between nucleotide sequences spanning nt -2634 to nt -1 of UCP1 gene of various animal species.

Fig. 3. Comparison of the amino acid sequence deduced from the nucleotide sequence of PGC-1, PPAR $\beta / \delta, T R \alpha, R X R \alpha$, CREB and NRF1

The partial gene transcripts of PGC- $1 \alpha, \mathrm{PGC}-1 \beta, \mathrm{PPAR} \beta / \delta, \mathrm{TR} \alpha, \mathrm{RXR} \alpha, \mathrm{CREB}$ and 
NRF1 were isolated and sequenced. The deduced amino acid sequences of PGC-1 $\alpha$ (A), PGC-1 $\beta$ (B), PPAR $\beta / \delta$ (C), TR $\alpha$ (D), RXR $\alpha$ (E) CREB (F) and NRF1 (G) were compared to that of fish PGC- $1 \alpha$, PGC- $1 \beta, \operatorname{PPAR} \beta / \delta, \mathrm{TR} \alpha, \mathrm{RXR} \alpha, \mathrm{CREB}$ and NRF1, respectively. The dot stands for the same amino acid as that in Cca. Cca: Cyprinus carpio, Cau: Carassius auratus, Dre: Danio rerio, Cid: Ctenopharyngodon idella, Spr: Schizothorax prenanti, Ncr: Notemigus crysoleucas, Ssa: Salmo salar, Caca: Carassius carassius, Omy: Oncorhynchus mykiss, Pma: Pagrus major, Ola: Oryzias latipes. $\beta / \delta, \beta, \beta 2$ and $\delta$ b: $\operatorname{PPAR} \beta / \delta$, PPAR $\beta, \operatorname{PPAR} \beta 2$ and PPAR $\delta$ b, respectively. $\alpha 1$, $\alpha 2$ and $\alpha \mathrm{A}: \mathrm{TR} \alpha 1, \mathrm{TR} \alpha 2$ and $\mathrm{TR} \alpha \mathrm{A}$, respectively.

Fig. 4. PGC-1 expression in the livers and kidneys of common carps acclimated to various temperatures

Common carps acclimated at $22^{\circ} \mathrm{C}$ were subjected to cold exposure for 14 days at $8^{\circ} \mathrm{C}$. They were then acclimated at $28^{\circ} \mathrm{C}$ for 14 days. Transcript levels of PGC- $1 \alpha$ (A) and PGC-1 $\beta$ (B) were determined by RT-qPCR and are expressed relative to the expression of EF1 $\alpha$, with the hepatic level determined on day 0 (control) set to 100. Data shown are the mean \pm SE $(n=10)$. a, b: $P<0.05$.

Fig. 5. Expression of PPAR, TR $\alpha$ and RXR $\alpha$ in the livers and kidneys of common carps acclimated to various temperatures

Common carps acclimated at $22^{\circ} \mathrm{C}$ were subjected to cold exposure for 14 days at $8^{\circ} \mathrm{C}$. They were then acclimated at $28^{\circ} \mathrm{C}$ for 14 days. Transcript levels of PPAR $\alpha$ (A), PPAR $\beta / \delta$ (B) PPAR $\gamma(\mathrm{C}), \mathrm{TR} \alpha(\mathrm{D})$ and RXR $\alpha$ (E) were determined by RT-qPCR and are expressed relative to the expression of EF1 $\alpha$, with the hepatic level determined on day 0 (control) set to 100. Data shown are the mean \pm SE $(n=10)$. A, B, C and a, b, c: $P$ $<0.05$. 
Fig. 6. Expression of CREB and NRF1 in the livers and kidneys of common carps acclimated to various temperatures

Common carps acclimated at $22^{\circ} \mathrm{C}$ were subjected to cold exposure for 14 days at $8^{\circ} \mathrm{C}$. They were then acclimated at $28^{\circ} \mathrm{C}$ for 14 days. Transcript levels of CREB (A) and NRF1 (B) were determined by RT-qPCR and are expressed relative to the expression of EF1 $\alpha$, with the hepatic level determined on day 0 (control) set to 100. Data shown are the mean \pm SE $(\mathrm{n}=10)$. A, B, C and a, b, c: $P<0.05$. 
Fig. 1

\section{UCP1}

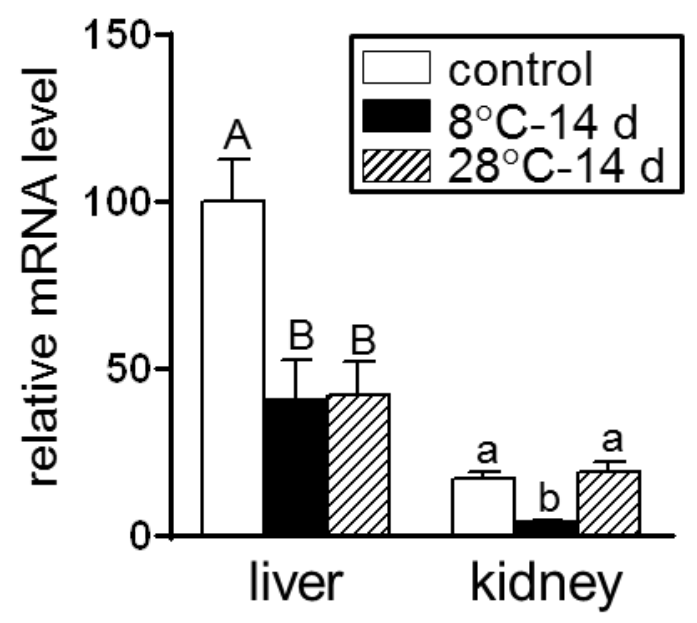




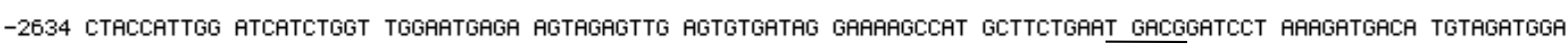

-2534 GARGTAARGT GGTCCAAGCA CTGAGCCCTG AGGAACCCCA GTAGCTTAGG TGGTAACAAC GCCTGGATGT GTTATTTATT TATTTATTTA TTATTATTAT

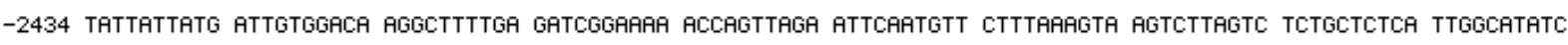
-2334 TGGCCTGATt TTCCCTTGAT ARAGTGTTCC TGCTGGTTCA GGAGCGGCTG TAGGACAGTC AGCAGATGAC TGAAGATAAT GCTCCAGCTG CTGCTGGTGT

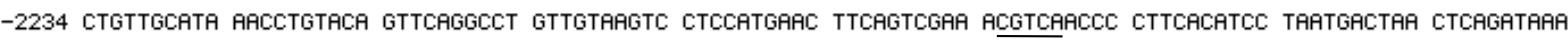
-2134 CATTAGACCA GTACTAGACC ACTTCACAGT CCGGATCCAG TCCTTCTGAG AGAGATCAGA CTATCAGTGA AGCTGAAGTC TTCATATTAG ATTGACARAC

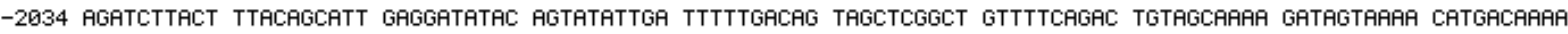

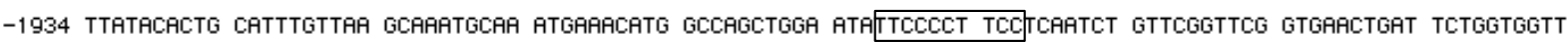

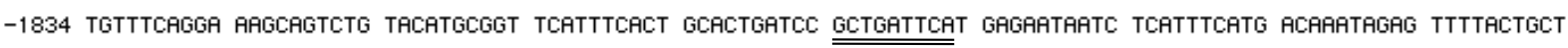
-1734 GCtTTTATGT AGTARARTGT TTAGTTACAT GATATTAATA ATCACAATTC AGTATTATTT TGGGTTCTTT TGGATARAGG tGTATGTTTG GGTTARAGAT -1634 TAATGCTGTG CTGTCACTCT GGCTGAGATC ATTGTTTGTG TGCCATARAA ATACATGTTT TTRARARTAC ATATARTCTG ACTATTATCT ARACGATATT

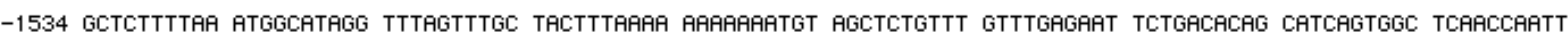

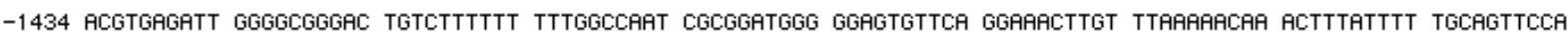
-1334 CTTCAGGAAT CACATACTTC ARCTTTAACA GTTCTTTTAT ATTCAATTCA ATTTAGAACT ATATCTGTCC GAAGAATTAT TACCATTGCT ATTATTACTA

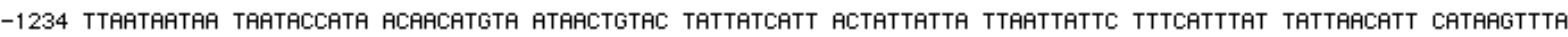

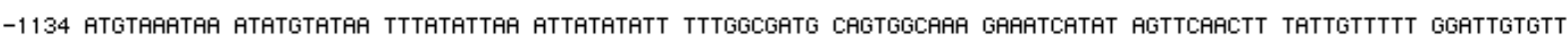

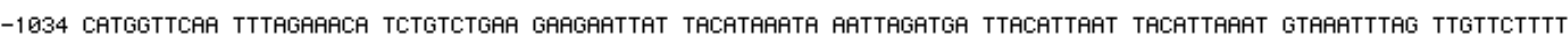

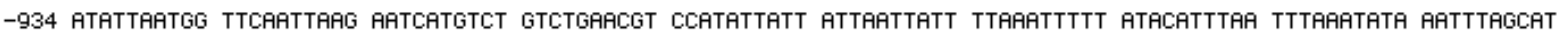

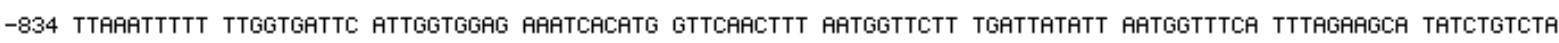
-734 AACAACCCTT ARGGTTCTTG ACTTGTARTG AGTATTATTT ARTTTTTTTT TAGTTTTAAT GAGCAGAACA TGTTTGTTGA GGATCATCGA GTTTGTGTTG

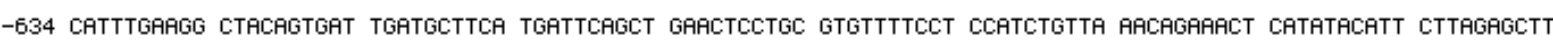
-534 TGTTATTTGG CTCATATTTT ACCGTTTCCC ACCCTTCCAA GAGGCCARTC ATCTTTCAGA CCCTGCAGGA CTGTCCCTGC GCTGCTATTG GCTGACAGCT

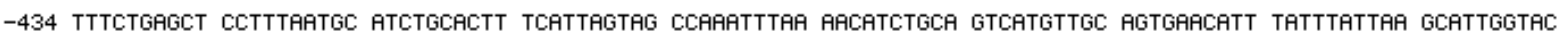

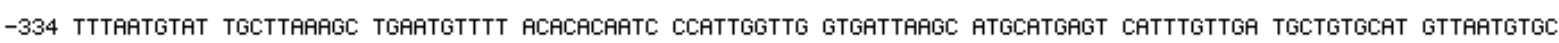

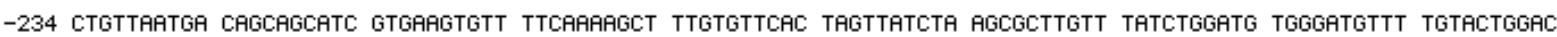
-134 TCTGTGCTGG AAGGTGGACT TTGTGTCGGC CAGTAATCTT TCCCTGAGAR ACACCTCCCT GAGCGGAGGA GGAAGAACCC CTCTTGGATA ATGATATATA -34 AAGARAGACA GAGCATGCCC TCGTCCCTCC AGAGCTCCAG TCATCATCCT GTCACTCCAT CAGACAGAGG AACTCAATCA CAGGTCAGTT CACCATGTTT 
B

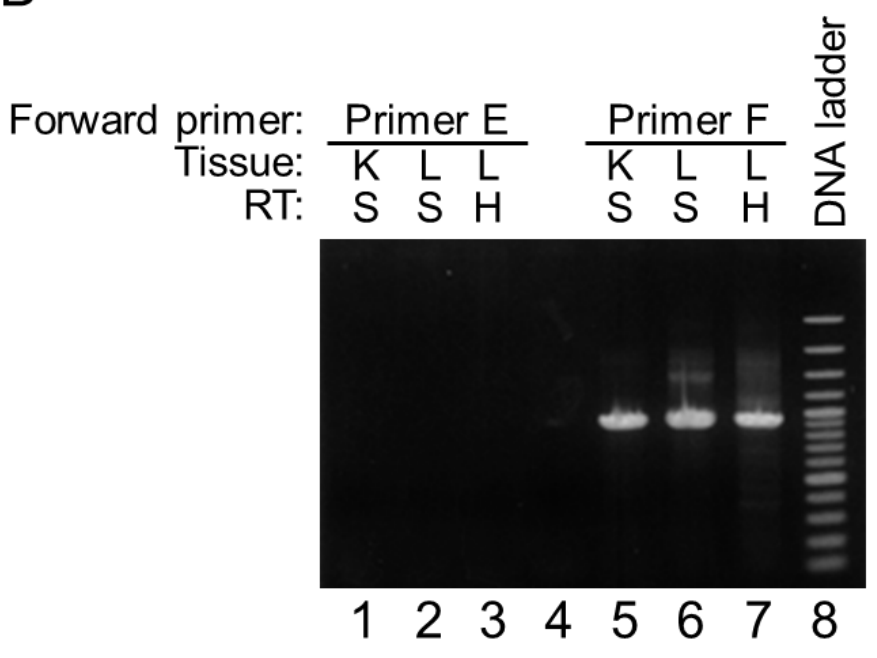

Fig. 2B, C

C

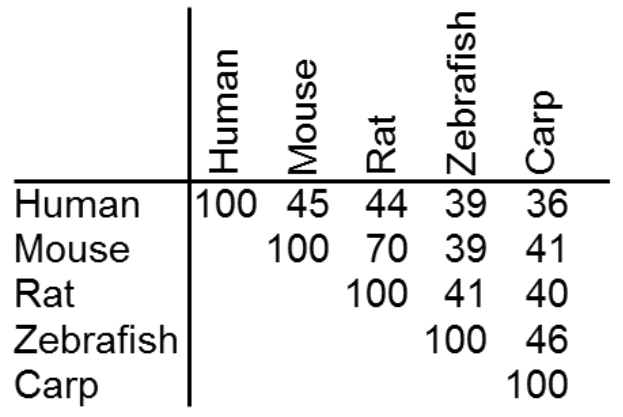


A

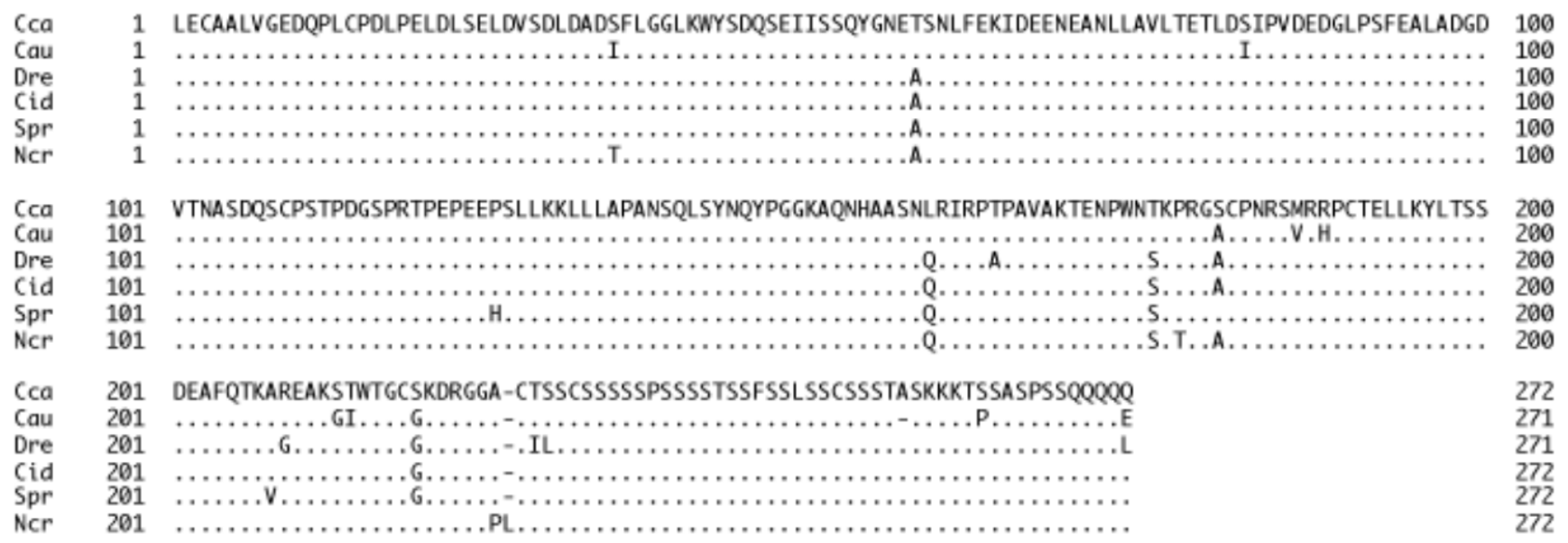

B

CCa 1 ELSSFVFNYLTENSGSQYGEEEVCSDRLDADFPDFDLSQLDASDFDSVNCLSELHWCNEHSDHSPASIQYSGGNPELFE-E-ENAALLAALTDSLDG

Cau 1 ( 1 E.

Dre $\quad 1$. $\quad 1$.

Ssa $\quad 1$. 1 .

Fig. 3A-C

C

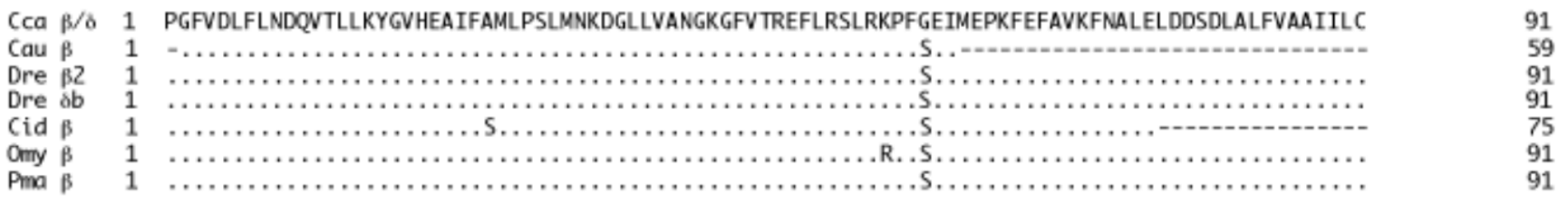


Fig. 3D-G

D

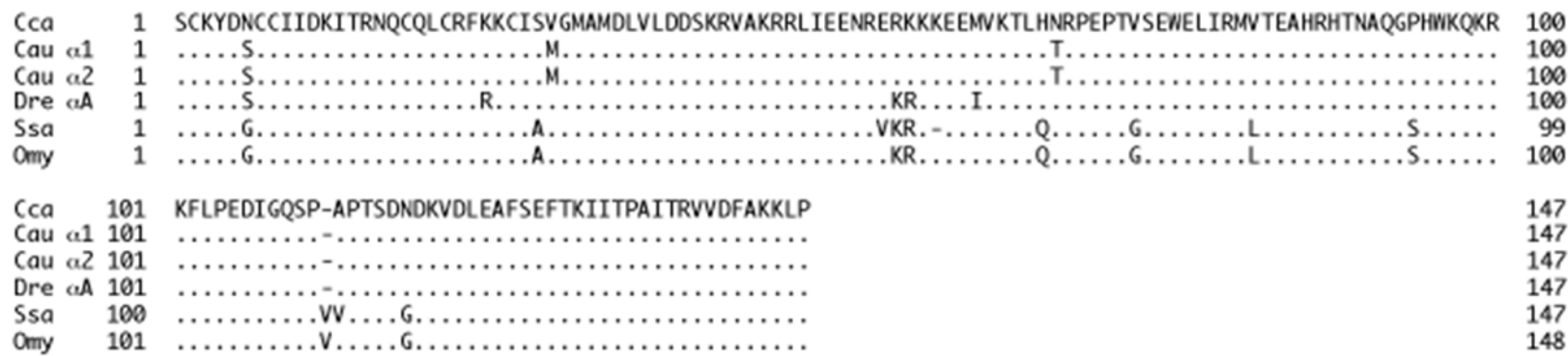

$E$

Cca 1 VEPKTETYIETNVPMPSNSPNDPVTNICQAADKQLFTLVEWAKRIPHFSELPLDDQVILLRAGWNELLIASFSHRSIAVKDGILLATGLHVHRNSAHSAG 100

CaU 1 Va

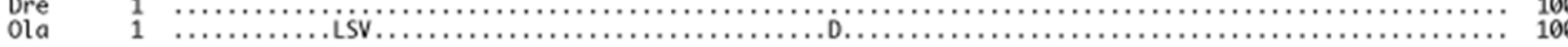

CCa 101 VGAIFDRVLTELVSKMRDMOMDKTELGCLRAIVLFNPDSKGLSNPGEVE

Cau 101 ............................................

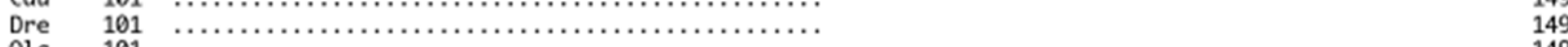

F

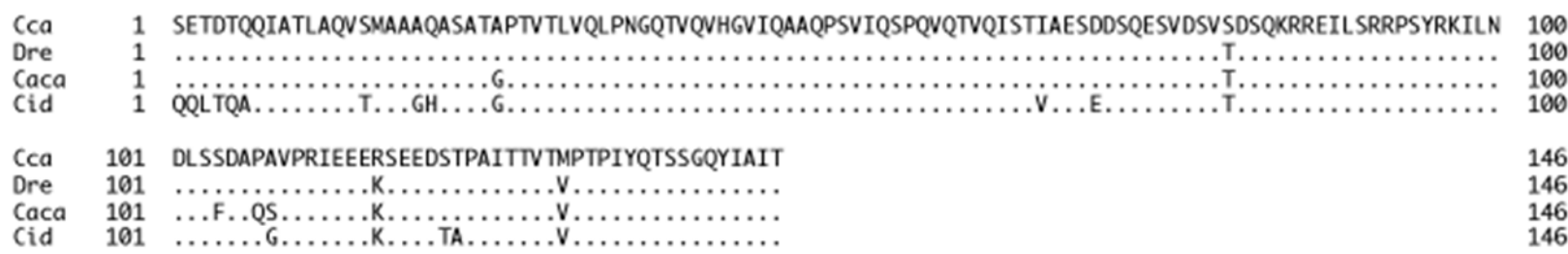

G

\begin{tabular}{|c|c|c|c|}
\hline Cca & 1 & PEMLKYSTGRGKPGWGKESCKPIWWPEDIPWANVRSDVRTEEQKQRV SWTQALRTIVKNCYKQHGREDLLYAFEDQITTQQVATTTTHSIAHLVPSQTVV & 100 \\
\hline Dre & 1 & & 99 \\
\hline Cid & 1 & & 100 \\
\hline Cca & 101 & QTISNPDGTVSLIQVGTGATVATLADASELPGTVTVAQVNYSTVTDGEVEQNNATLQGGEMTIQTTQP & \\
\hline Dre & 100 & 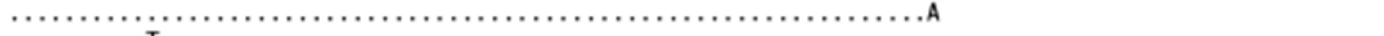 & \\
\hline Cid & 101 & 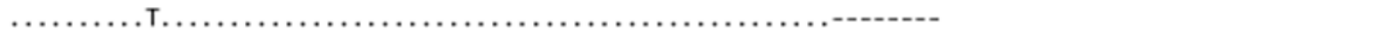 & \\
\hline
\end{tabular}


Fig. 4

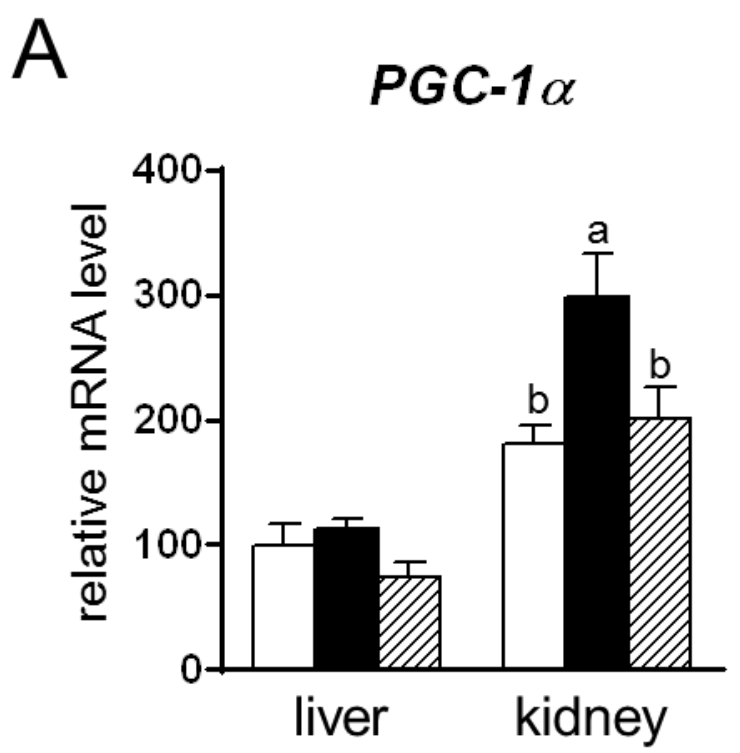

B
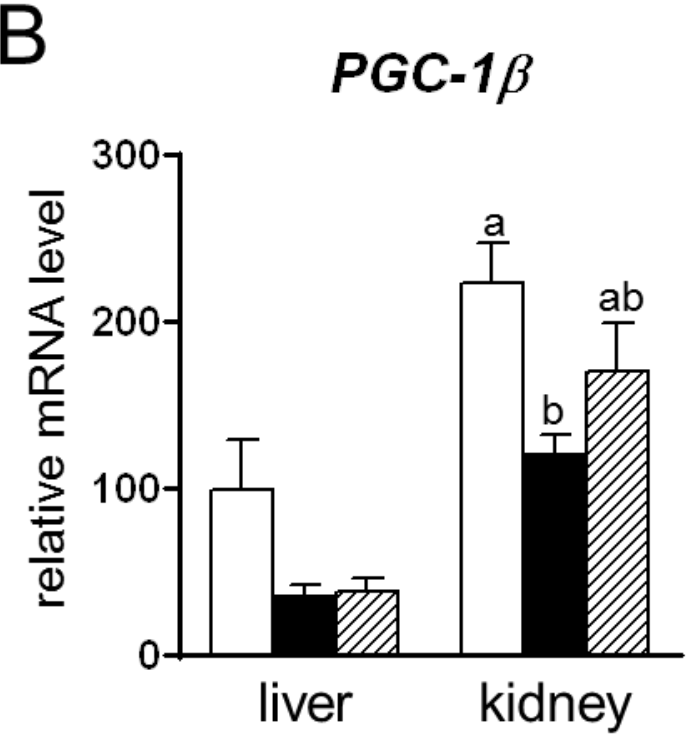
A

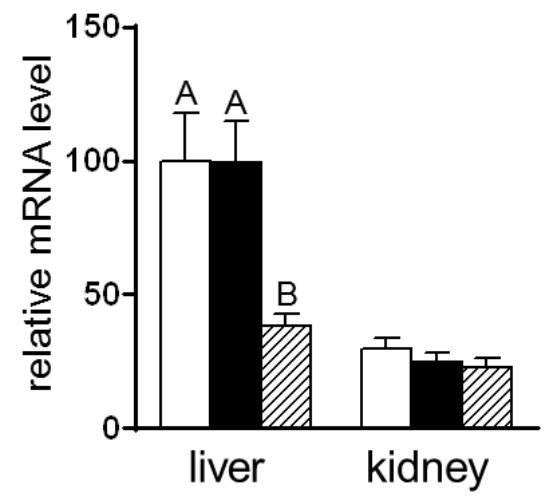

D

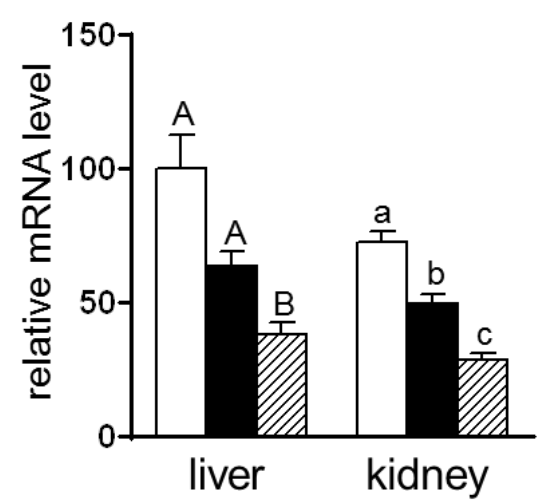

B

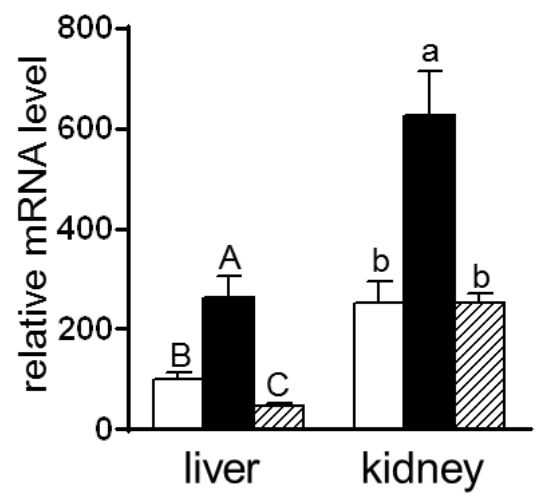

$E$

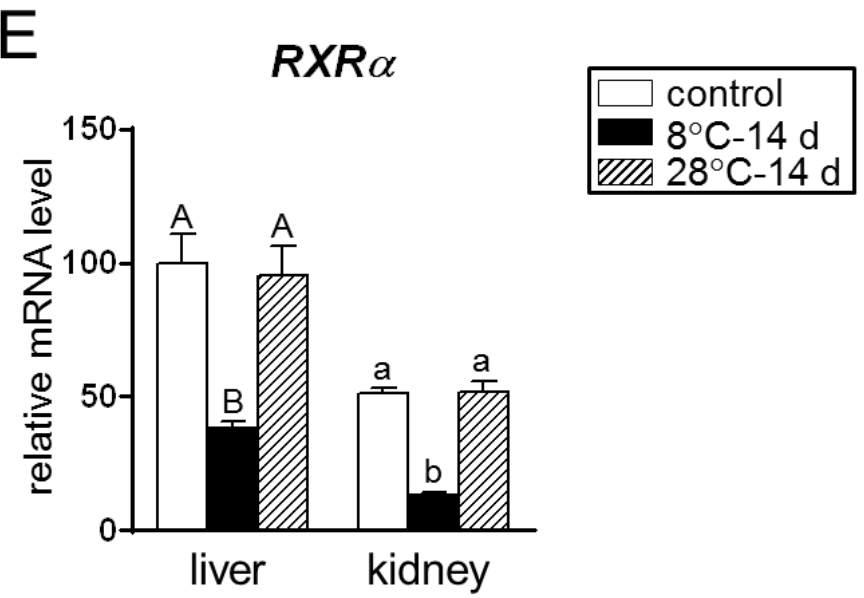

Fig. 5

PPAR $\gamma$

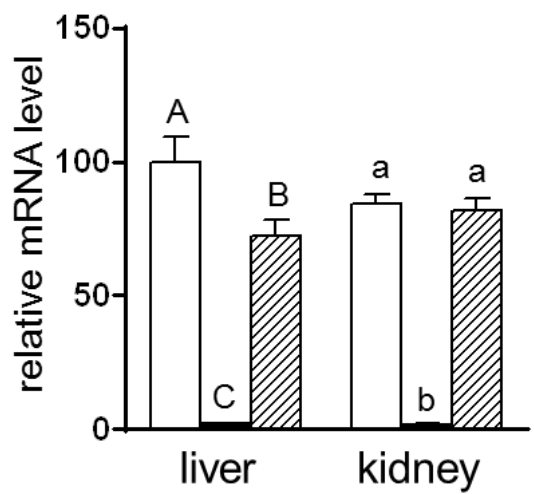


A

CREB

B
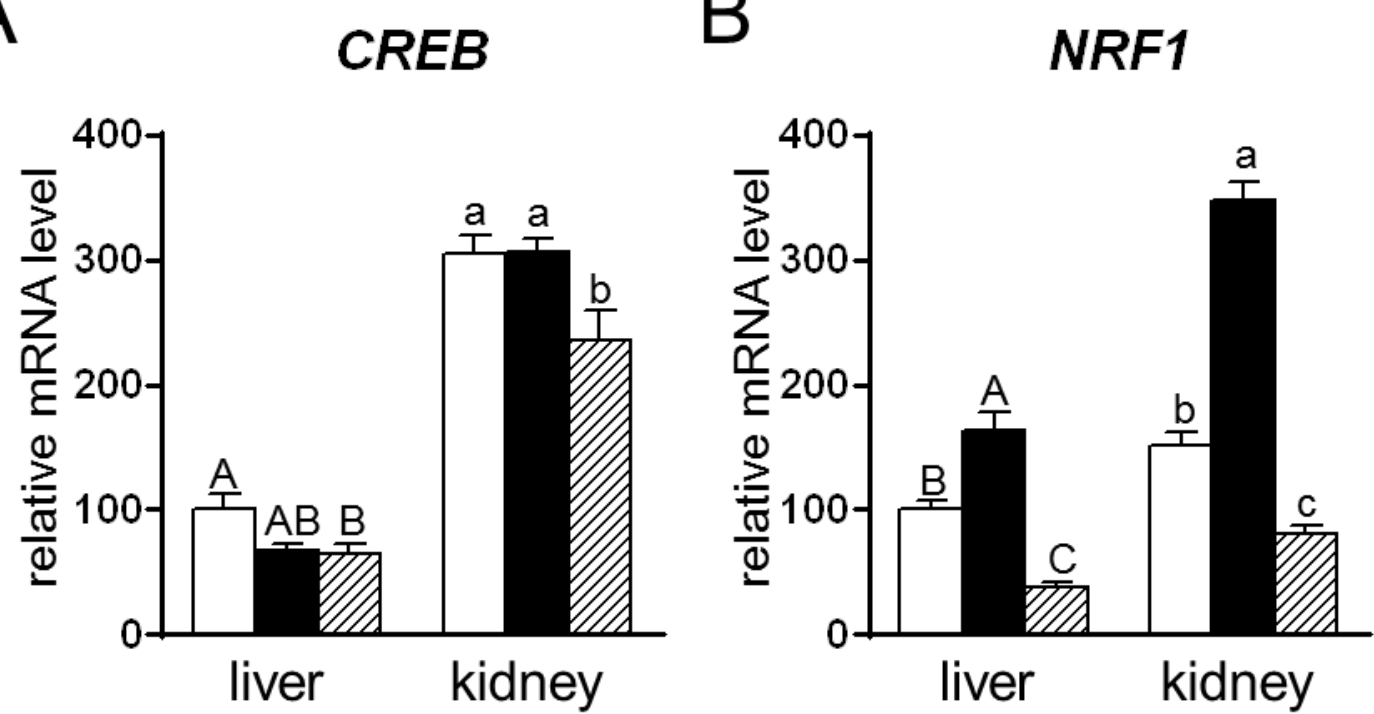

Fig. 6 
Table 1. Nucleotide sequence of primers used in RT-qPCR analyses

\begin{tabular}{|c|c|c|c|}
\hline Gene & Forward primer & Reverse primer & $\begin{array}{l}\text { GenBank } \\
\text { accession number }\end{array}$ \\
\hline CREB & 5'-ctcagcagattgccaccttgg-3' & 5'-gggcagctgaactaaggtcac-3' & $\mathrm{LC}^{2} 000680^{1}$ \\
\hline EF1 $\alpha$ & 5'-atgcggtggaatcgacaa-3' & 5'-cagagagcaatgtcaatggtg-3' & AF485331 \\
\hline NRF1 & 5'-aagccctgaggactattgtt-3' & 5'-gctcctgtgccaаcctgtat-3' & AB924641 ${ }^{1}$ \\
\hline PGC-1 $1 \alpha$ & 5'-tgcctgagcttgacctctct-3' & 5'- cgtcttcatccactgggatac-3' & $\mathrm{AB} 67302^{1}$ \\
\hline PGC-1 $\beta$ & 5'-tggggaagaggaggtctgc-3' & 5'-ccgtccaggctgtctgtg-3' & $\mathrm{AB} 67303^{1}$ \\
\hline PPAR $\alpha$ & 5'-gggaaagagcagcacgagtcc-3' & 5'-ggtaggcttcatgcatctgtc-3' & FJ849065 \\
\hline $\mathrm{PPAR} \beta / \delta$ & 5'-tggctttgtggatctcttcc-3' & 5'-gatctcgccgaaaggtttgc-3' & $\mathrm{LC}^{0} 00683^{1}$ \\
\hline $\operatorname{PPAR} \gamma$ & 5'-aggcaactctacgagtcctatct-3' & 5'-agttgatcatctgctcgccttcc-3' & FJ849064 \\
\hline $\mathrm{RXR} \alpha$ & 5'-cacccaatgatccagtcacaaaca-3' & 5'-agctcattccatcctgctcgtaga-3' & $\mathrm{LC}^{2} 000682^{1}$ \\
\hline $\mathrm{TR} \alpha$ & 5'-aatcacccgcaaccagtgccag-3' & 5'-tcgatcagacgcctcttggcc-3' & $\mathrm{LC}^{0} 00681^{1}$ \\
\hline UCP1 & 5’-cgccttctacaaaggtttcg-3' & 5’-cgaatgacacgaacatcacc-3’ & AY461434 \\
\hline
\end{tabular}

${ }^{1}$ Nucletotide sequence was determined in this study. 
Fig. 1

\section{UCP1}

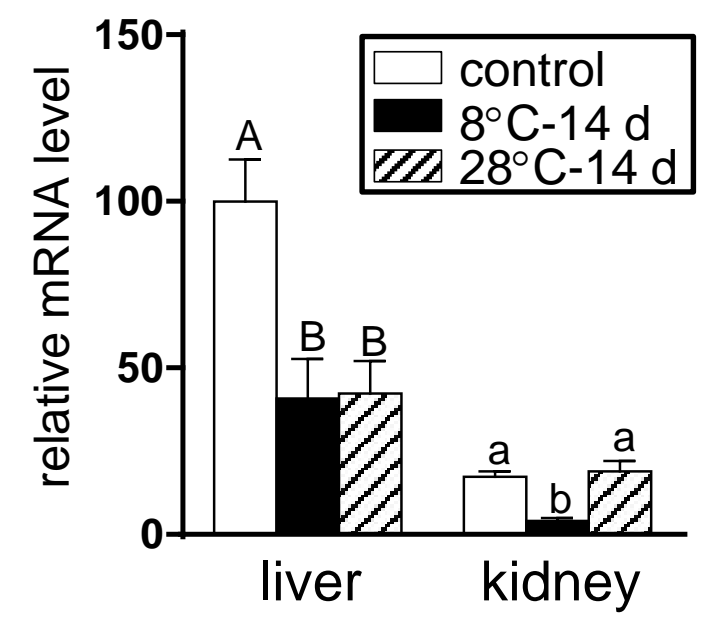




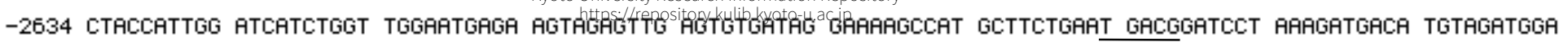
-2534 GAAGTARAGT GGTCCAAGCA CTGAGCCCTG AGGAACCCCA GTAGCTTAGG TGGTAACAAC GCCTGGATGT GTTATTTATT TATTTATTTA TTATTATTAT

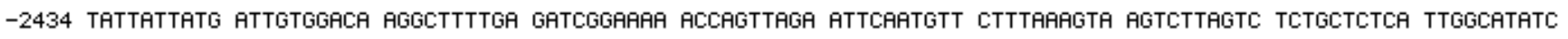
-2334 TGGCCTGATt TTCCCTTGAT ARAGTGTTCC TGCTGGTTCA GGAGCGGCTG TAGGACAGTC AGCAGATGAC TGRAGATRAT GCTCCAGCTG CTGCTGGTGT -2234 CTGTTGCATA AACCTGTACA GTTCAGGCCT GTTGTAAGTC CTCCATGAAC TTCAGTCGAA ACGTCAACCC CTTCACATCC TAATGACTAR CTCAGATAAA

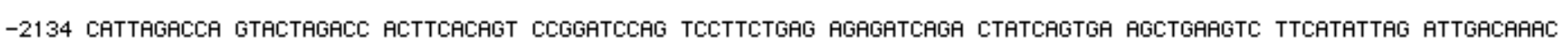

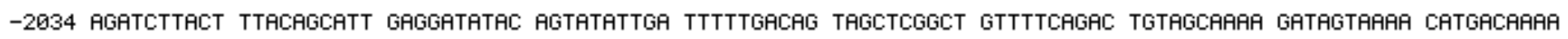

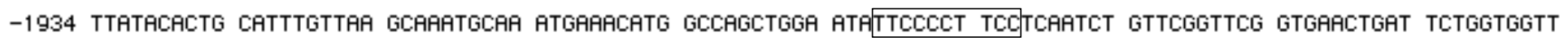
-1834 TGTTTCAGGA ARGCAGTCTG TACATGCGGT TCATTTCACT GCACTGATCC GCTGATTCAT GAGARTARTC TCATTTCATG ACAARTAGAG TTTTACTGCT -1734 GCTTTTATGT AGTARAATGT TTAGTTACAT GATATTAATA ATCACAATTC AGTATTATTT TGGGTTCTTT TGGATAARGG TGTATGTTTG GGTTARAGAT -1634 TARTGCTGTG CTGTCACTCT GGCTGAGATC ATTGTTTGTG TGCCATARAA ATACATGTTT TTARAFATAC ATATAATCTG ACTATTATCT ARACGATATT

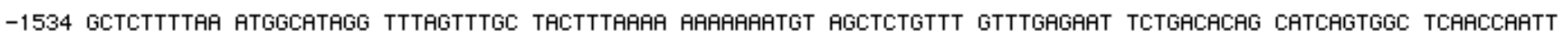
-1434 ACGTGAGATT GGGGCGGGAC TGTCTTTTTT tTTGGCCAAT CGCGGATGGG GGAGTGTTCA GGAFACTTGT TTARAFACAR ACTTTATTTT TGCAGTTCCA -1334 CTTCAGGAAT CACATACTTC AACTTTAACA GTTCTTTTAT ATTCAATTCA ATTTAGRACT ATATCTGTCC GARGAATTAT TACCATTGCT ATTATTACTA

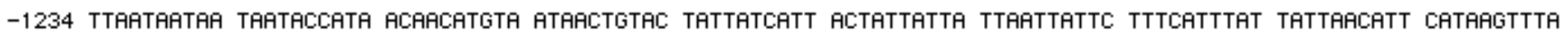

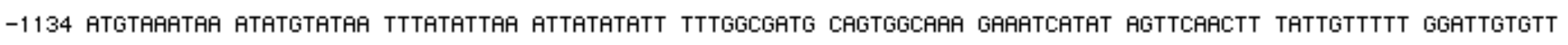

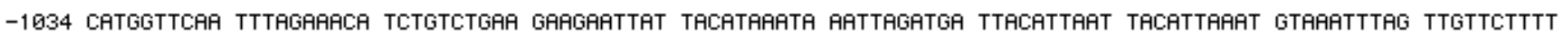

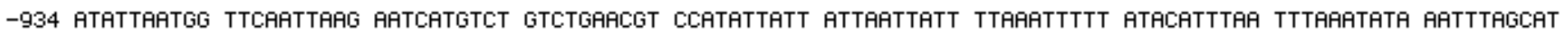

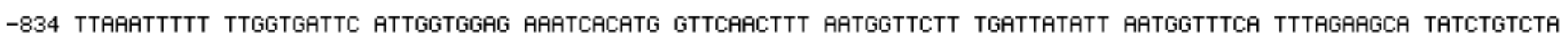
-734 AFCAACCCTT ARGGTTCTTG ACTTGTARTG AGTATTATTT AATTTTTTTT TAGTTTTAAT GAGCAGAACA TGTTTGTTGA GGATCATCGA GTTTGTGTTG

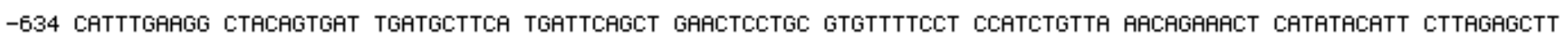

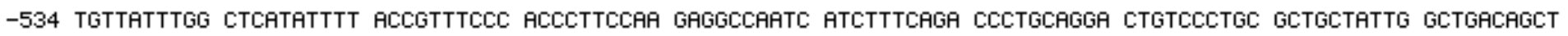

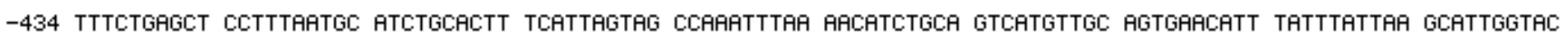

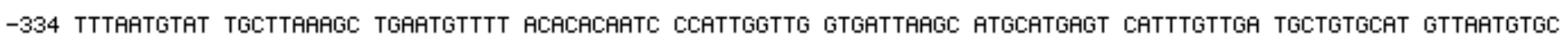

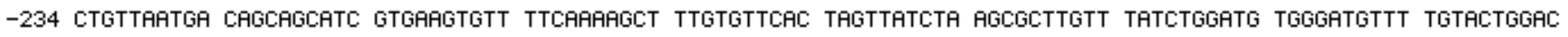
-134 TCTGTGCTGG AAGGTGGACT TTGTGTCGGC CAGTAATCTT TCCCTGAGAA ACACCTCCCT GAGCGGAGGA GGAAGAACCC CTCTTGGATA ATGATATATA

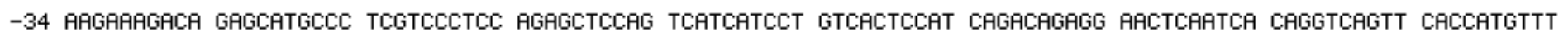


Fig. 2B, C

B

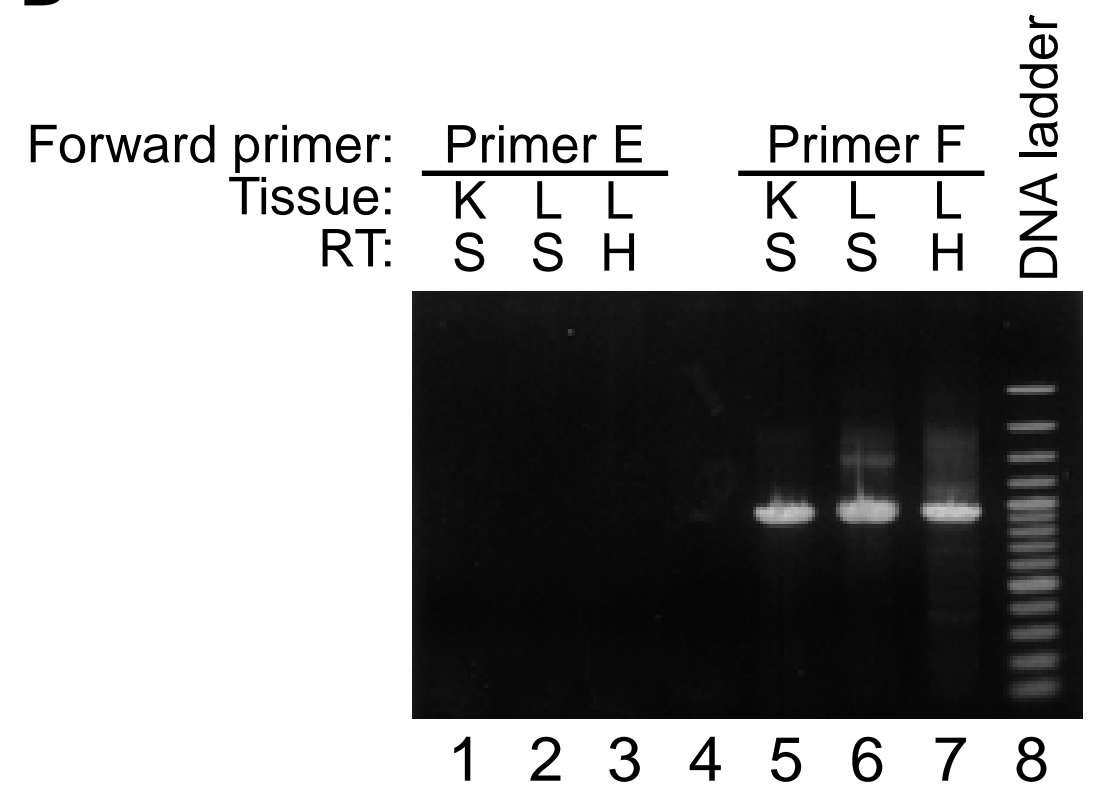

C

\begin{tabular}{|c|c|c|c|c|c|}
\hline & 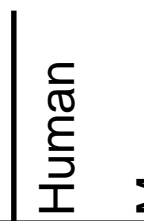 & 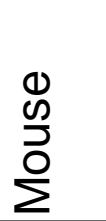 & $\begin{array}{l}\mathbb{\pi} \\
\widetilde{\simeq}\end{array}$ & 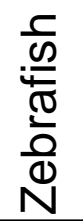 & $\stackrel{0}{\frac{0}{0}}$ \\
\hline Human & 100 & 45 & 44 & 39 & 36 \\
\hline Mouse & & 100 & 70 & 39 & 41 \\
\hline Rat & & & 100 & 41 & 40 \\
\hline Zebrafish & & & & 100 & 46 \\
\hline Carp & & & & & 100 \\
\hline
\end{tabular}


A

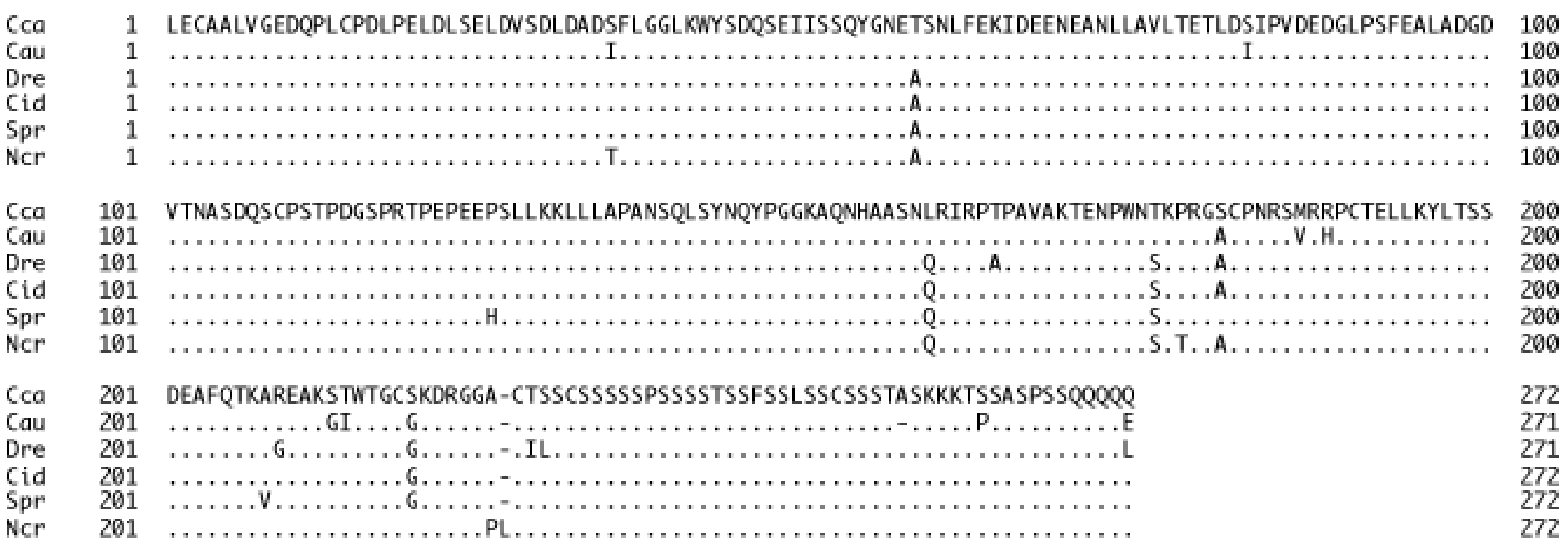

B

C 
$\mathrm{D}$

\begin{tabular}{|c|c|c|}
\hline $\mathrm{Cca}$ & 1 & SCKYDNCCIIDKITRNQCQLCRFKKCISVGMAMDLVLDDSKRVAKRRLIEENRERKKKEEMVKTLHNRPEPTVSENELIRMVTEAHRHTNAQGPHWKQKR \\
\hline Cau a1 & 1 & 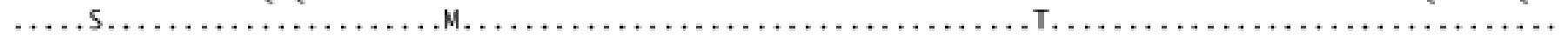 \\
\hline Cau a2 & 1 & 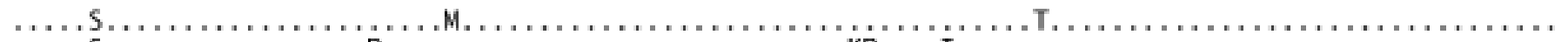 \\
\hline Dre aA & 1 & 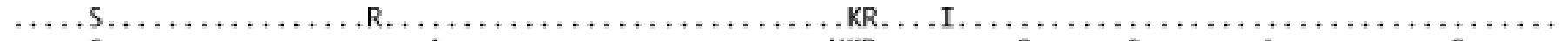 \\
\hline Ssa & 1 & 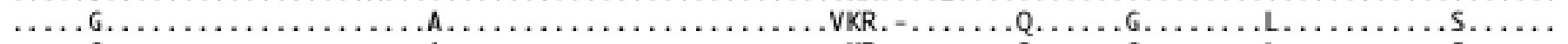 \\
\hline Omy & 1 & 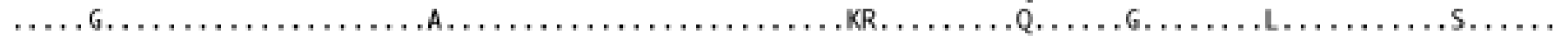 \\
\hline Cca & 101 & KFLPEDIGQSP-APTSDNDKVDLEAFSEFTKIITPAITRVVDFAKKLP \\
\hline Cau a1 & 101 & 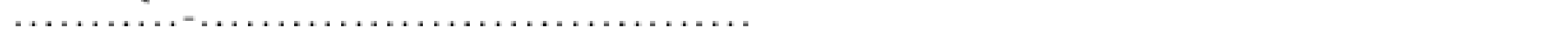 \\
\hline Cau o. & 101 & 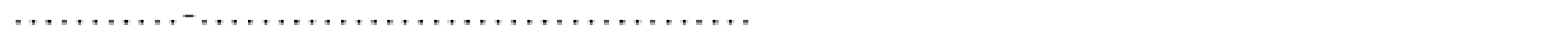 \\
\hline Dre aA & 101 & 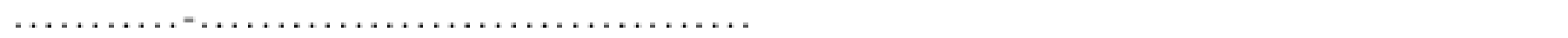 \\
\hline Ssa & 100 & 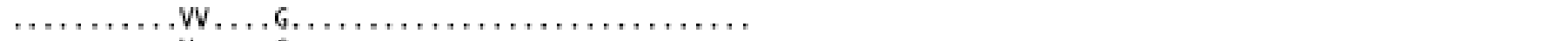 \\
\hline Omy & 101 & 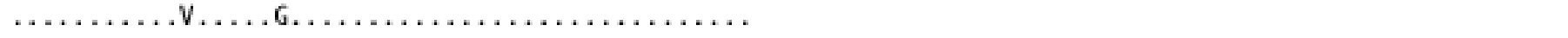 \\
\hline
\end{tabular}

$E$

$\begin{array}{ll}\text { Cca } & 1 \\ \text { Cau } & 1 \\ \text { Dre } & 1\end{array}$

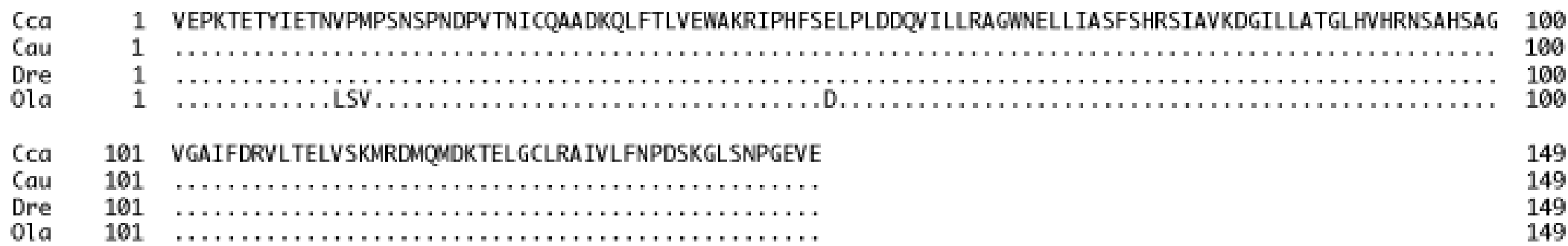


Fig. 4
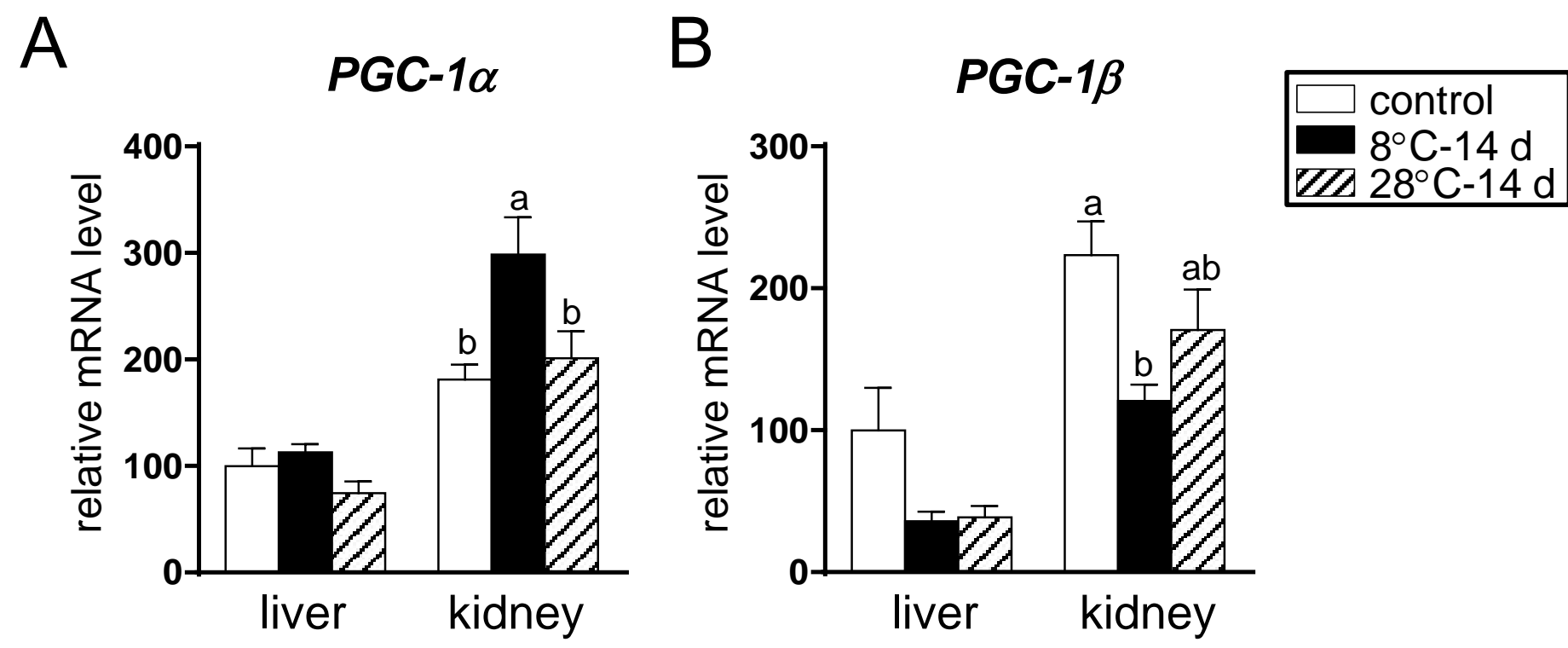
A

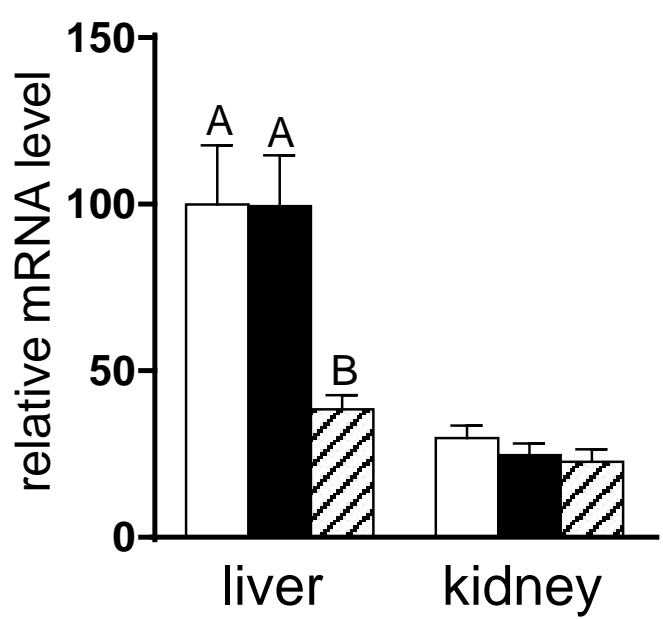

D

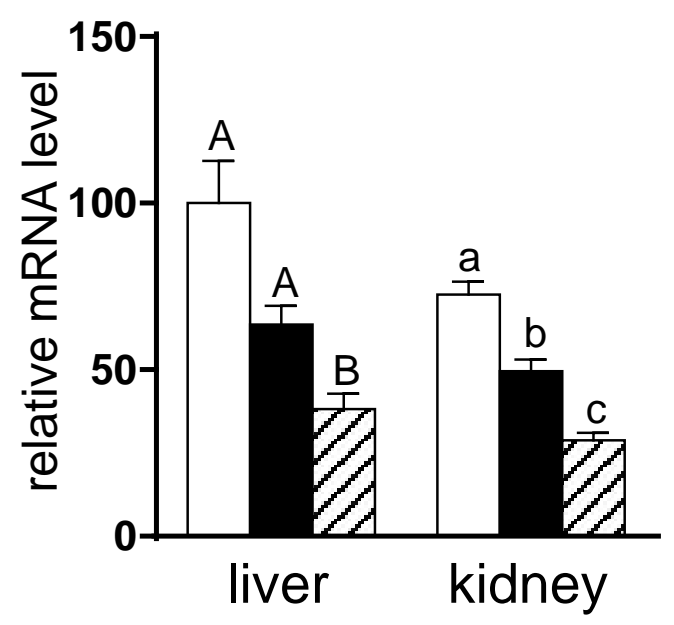

B

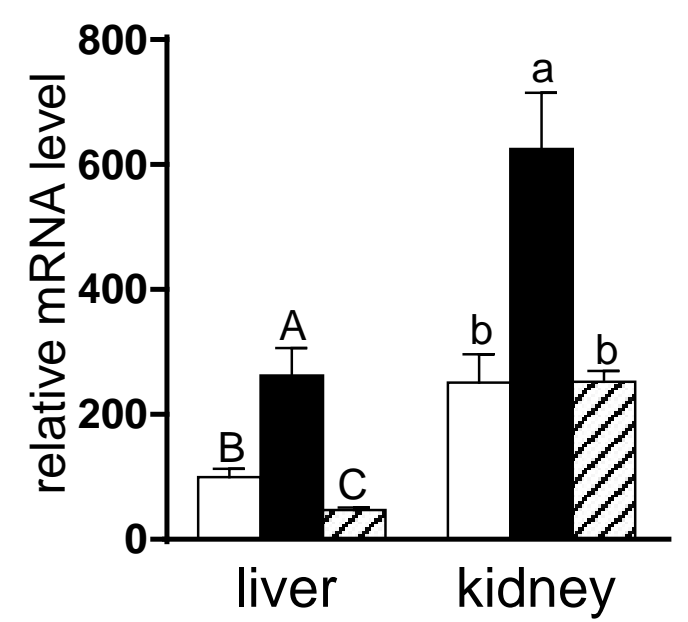

E

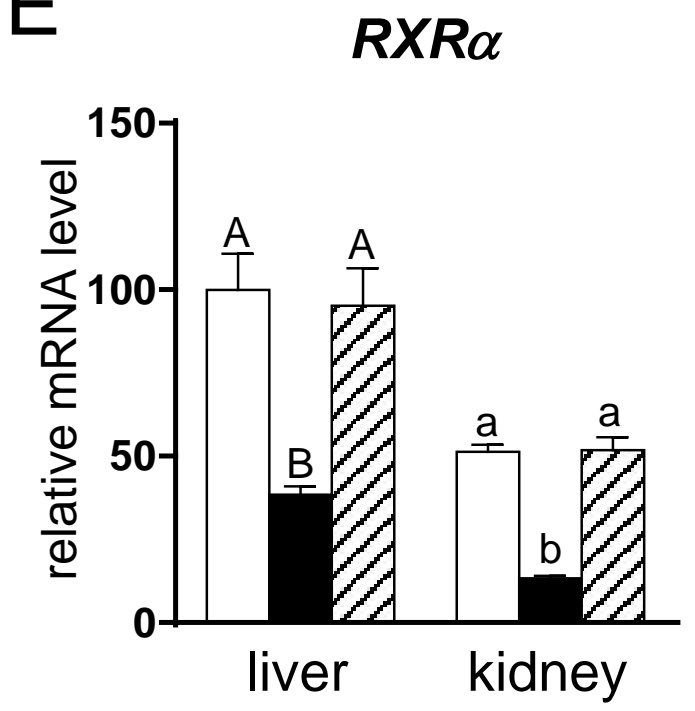

Fig. 5
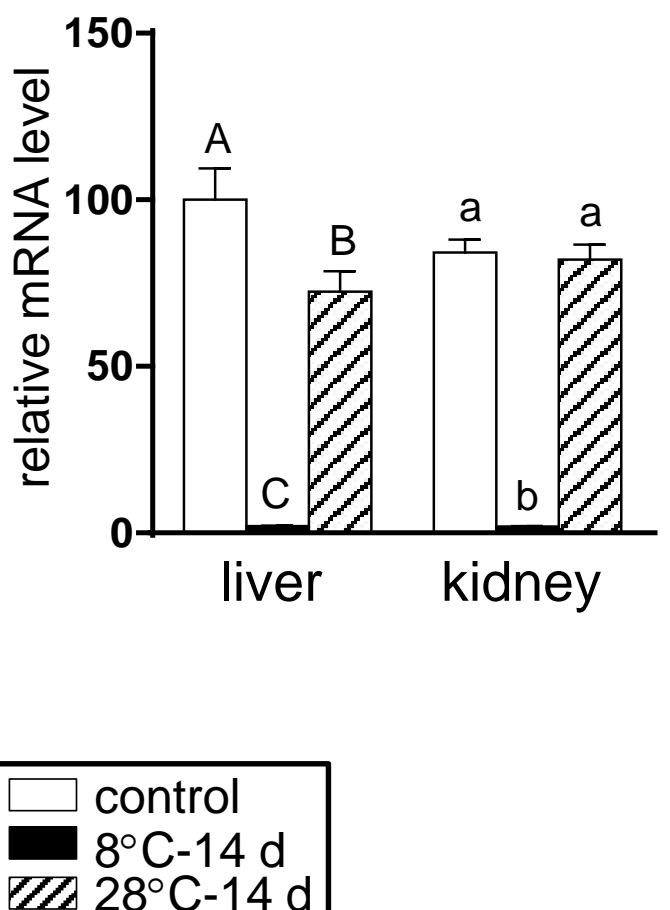

VI/ 28 $8^{\circ} \mathrm{C}-14 \mathrm{~d}$ 
Fig. 6
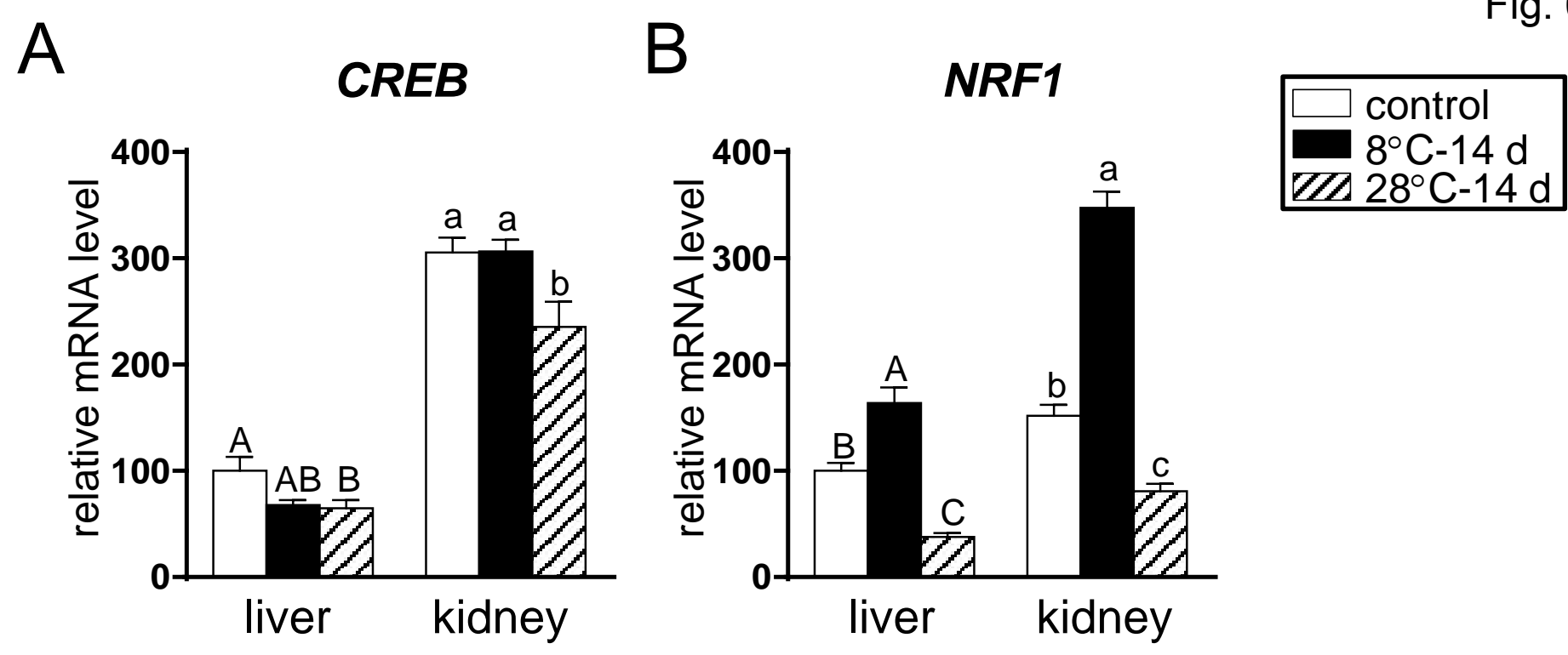